\title{
How do albatrosses fly around the world (almost) without flapping their wings?
}

\author{
Philip L. Richardson \\ Department of Physical Oceanography MS\#29 \\ Woods Hole Oceanographic Institution \\ 360 Woods Hole Road \\ Woods Hole, MA 02543 USA
}

August 26, 2010

E-mail address: prichardson@whoi.edu

Tel: 5082892546

Fax: 5084572163 


\begin{abstract}
Albatrosses fly long distances over the Southern Ocean, even around the world (almost) without flapping their wings, which has raised interest in how they perform such a feat. On a cruise to the South Atlantic I observed albatrosses soaring in a characteristic swooping zigzag flight that appears to combine two soaring techniques to gain energywind-shear soaring (dynamic soaring) using the vertical gradient of wind velocity and wave-slope soaring using updrafts over waves. The observed characteristic swooping flight is shown in a new illustration and interpreted in terms of the two soaring techniques. The energy gain estimated for "typical conditions" in the Southern Ocean suggests that wind-shear soaring provides around 80-90\% of the total energy required for sustained soaring. A much smaller percentage is provided by wind shear in light winds and significant swell when wave-slope soaring dominates. A simple dynamical model of wind-shear soaring is proposed based on the concept of a bird flying across a sharp windshear layer as first described by Lord Rayleigh in 1883 and later developed with Pennycuick's (2002) description of albatrosses "gust soaring." In gust soaring a bird exploits structures in the wind field, such as separated boundary layers and eddies in the lee of wave crests, to obtain energy by climbing headed upwind and descending headed downwind across a thin wind-shear layer. Benefits of the model are that it is simple to understand, it captures the essential dynamics of wind-shear soaring, and it provides reasonable estimates of the minimum wind shear required for travel velocity in different directions with respect to the wind. Travel velocities, given in a travel velocity polar diagram, can be combined with tacking to fly in an upwind direction faster than the wind speed located at the top of the wind-shear layer.
\end{abstract}




\section{Introduction}

Albatrosses fly long distances over the Southern Ocean, even around the world (almost) without flapping their wings (Croxall et al., 2005; Safina, 2002, 2007). How they soar for such long times has intrigued observers, who have often speculated as to how an albatross can extract energy from the wind. Two theories have been proposed to explain how the birds fly without flapping their wings. The first, which has gained prominence, proposes that an albatross uses wind shear, the increase in wind speed with height above the ocean surface, to gain energy (wind-shear soaring). The second theory proposes that an albatross uses updrafts caused by wind blowing over waves to gain energy (wave-slope soaring).

Wind blowing over waves has both wind shear and vertical motions, so the individual effects are not easily separated. Wind interacting with waves often contains structures such as gusts, lee eddies and rolls, which have updrafts and wind shear. Since wind generates waves, given sufficient time wind waves coexist with wind shear in the open ocean. In the Southern Ocean where most albatrosses soar there are strong winds and large waves, including both locally-generated wind waves and swell waves generated elsewhere. All mathematical model studies of albatross flight in wind shear assume horizontal winds and no waves thus excluding the effect of wave-slope soaring and lee eddies which the birds appear to use effectively. In addition, most models assume either a linear, logarithmic, or exponential vertical profile of average wind, which can be very different from the structure of the instantaneous wind field as it interacts with waves. Even with these simplifying assumptions, the resulting aerodynamical differential equations describing the accelerated twisting, turning, swooping flight of albatrosses in wind shear are very complex (Lissaman, 2005; Sachs, 2005), which makes it difficult to understand the details and relevant dynamics of their flight.

The approach here is to use the characteristics of an observed swoop to estimate the energy gained from each soaring technique and to develop a simple dynamical model of wind-shear soaring based on Rayleigh's (1883) concept of a bird soaring across a sharp 
wind-shear layer, on Pennycuick's (2002) observations and description of albatrosses "gust soaring" across thin wind-shear layers in the lee of waves, and on the aerodynamical equations of motion (Lissaman, 2005). The modeled flight pattern is referred to here as the Rayleigh cycle because he was first to describe the concept of wind-shear soaring. The model provides a relatively easy way to understand the essential dynamics of wind-shear soaring and provides predictions of soaring travel velocities, which agree well with observations of albatross flight and more complicated simulations (Lissaman, 2005; Sachs, 2005). The Rayleigh cycle, which uses two homogenous wind layers, is the most efficient way for a bird to gain energy from a wind profile and thus indicates the minimum amount of wind speed that can support sustained soaring or, more precisely, energy-neutral flight.

When an albatross flies in wind, the bird's airspeed is different from its ground speed. This should be kept in mind because airspeed, and not ground speed, is the quantity most relevant to flying. Aerodynamic forces on a bird depend on its airspeed not ground speed. To understand this, imagine trying to fly horizontally in a downwind direction with a large ground speed but near-zero airspeed (due to wind shear). In this situation if ground speed were used to calculate kinetic energy, there would appear to be sufficient energy to support flight, but without any airspeed, down you would go in a stall. The use of airspeed and ground speed leads to different conclusions about where kinetic energy is gained in wind-shear soaring. An increase of airspeed comes from crossing the windshear layer. Most increase of ground speed occurs as a bird turns from a direction headed upwind to downwind. This difference complicates interpretations of energy conservation in soaring and has led to seemingly contradictory conclusions.

Gravity and drag relentlessly force a gliding albatross downward through the air. In balanced flight the bird's sinking velocity through the air represents the bird's rate of energy loss. In order to continuously soar, an albatross must extract sufficient energy from the atmosphere to balance the loss due to drag. No strong thermals exist in the high southern latitudes of the Southern Ocean where most albatrosses soar, so they extract energy from the wind using wind-shear soaring (also called dynamic soaring) and wave- 
slope soaring, which is somewhat similar to using the updrafts of wind blowing over a ridge. Albatrosses probably also exploit energy gained from gusts, updrafts and wind shear associated with turbulent winds.

\section{Observations}

I observed albatrosses soaring during a research cruise to the South Atlantic off Cape Town, South Africa in September 1997. It was surprising and delightful to see them almost magically soar upwind in wind speeds of 5-10 m/s (10-20 knots). The albatrosses flew in a characteristic and distinctive flight pattern consisting of a swooping motion where each swoop was tightly coupled to a wave crest (Fig. 1). Each swoop began with a fast flight parallel to and just above the windward side of a wave. This was followed by a turn into the wind and climb of around $10-15 \mathrm{~m}$, followed by a downwind descent towards another wave and a turn parallel to the wave. The typical time to complete a swoop was around $10 \mathrm{~s}$. These observations are largely in accord with previous studies (Alerstam et al., 1993; Idrac, 1925, 1931; Pennycuick, 1982). The close coupling between the swoops and waves suggests that wave-induced features of the wind field are important for sustained soaring, but these are often neglected in models of soaring flight.

I was not able to find a good schematic showing this pattern of albatross soaring, so I have tried to develop one. Figure 1 shows the zigzag swooping flight pattern in relationship to the waves. Each swoop is coupled to a wave as observed, although an Albatross can cross over intervening waves before pulling up over a wave. Wind shear and updrafts and downdrafts are indicated schematically in Figure 1, and under certain conditions the wind field can look somewhat like that shown. Often, however, the wind speed at a height of $10 \mathrm{~m}$ is only slightly faster than the wave phase speed. In that case wind vectors viewed in the frame moving with the waves reverse direction below a critical layer where the wind speed equals the wave speed. Structures such as lee eddies are ignored in Figure 1 for simplicity but can be important as mentioned later in describing details of albatross soaring. 
The goal of the paper is to interpret the observed flight pattern in terms of wind-shear soaring and wave-slope soaring as described below.

\section{Wind-shear soaring}

Average wind velocity generally increases with height from near zero velocity at the level of the ocean surface. The largest vertical gradient of wind velocity (largest wind shear) is located in a thin boundary layer located within around $2 \mathrm{~m}$ of the water surface (Fig. 2). Most of the increase of wind speed in an average wind profile is located in this thin wind-shear boundary layer near the surface. However, the structure of the wind field near the ocean surface is complicated by the presence of waves. Strong wind flowing over sharp-crested and breaking waves separates from the wave crest forming an area of weaker wind or a lee eddy just downwind of the wave crest (Fig. 3) as described by Pennycuick (2002). Located above this region of weak wind is a thin wind-shear region, a wind-shear boundary layer that has separated from the upwind wave crest, and above that a layer of stronger wind and reduced wind shear.

\subsection{Gust Soaring and Rayleigh cycle}

Pennycuick (2002) proposed that albatrosses take advantage of the strong wind shear located between these two layers downwind of sharp-crested waves in order to gain energy from the wind in what he calls "gust soaring," which is a special case of more general wind-shear soaring. A wind "gust" usually refers to a temporal variation of wind speed, but Pennycuick uses the term to mean the rapid increase of wind speed encountered by a bird as it climbs across the thin wind-shear layer located above a lee eddy. Gust soaring can be understood by using a two-layer approximation first described by Rayleigh (1883) in which a lower layer has zero wind speed and an upper layer has a uniform wind speed of $5 \mathrm{~m} / \mathrm{s}$ (for example) (Fig. 4). An albatross flying at a typical airspeed of $15 \mathrm{~m} / \mathrm{s}$ in an upwind direction in the lower layer pulls up a short distance into the upper layer encountering a "gust" of $5 \mathrm{~m} / \mathrm{s}$, which increases the bird's airspeed to 20 $\mathrm{m} / \mathrm{s}$ and adds a pulse of kinetic energy. If the albatross now descends back into the lower 
layer again without changing direction, the bird's airspeed would decrease back to 15 $\mathrm{m} / \mathrm{s}$, and there would be no net gain in kinetic energy to balance loss due to drag.

Albatross flight reveals that the trick of wind-shear soaring is to climb headed upwind, to then turn downwind, and to descend headed downwind. After rising into the upper layer and increasing airspeed to $20 \mathrm{~m} / \mathrm{s}$, the bird banks and turns downwind to fly in the opposite direction. If we ignore drag, which is small for an albatross, then just before descending, the bird's airspeed is $20 \mathrm{~m} / \mathrm{s}$ in a downwind direction and the (tail) wind speed is $5 \mathrm{~m} / \mathrm{s}$ also in a downwind direction. Thus, the bird's speed over the lower layer (ground speed) is $25 \mathrm{~m} / \mathrm{s}$, and when the bird descends into the lower layer airspeed increases to $25 \mathrm{~m} / \mathrm{s}$, adding another pulse of airspeed and kinetic energy. In order to continue gaining energy the bird could bank and turn toward the wind direction and climb up into the upper layer again. It is apparent that the bird could maximize the rate of gain of airspeed and kinetic energy by increasing the frequency of swoops. Several things tend to limit the airspeed of a real albatross: increased sinking rate with faster airspeeds and steeply banked turns, the physical strength of the bird as the aerodynamic force on its wings increases, and smaller wind shear compared to the step-like increase used in the example.

Some radio controlled (RC) glider pilots have recently used wind shear caused by strong winds blowing over ridges to fly gliders at surprisingly fast speeds. By repeatedly climbing upwind and descending downwind through the separated wind-shear layer located downwind of a ridge, $\mathrm{RC}$ gliders have achieved airspeeds over $150 \mathrm{~m} / \mathrm{s}$ in gust soaring (http://www.youtube.com/watch? $\mathrm{v}=\mathrm{Vi}$ i0hrjqU15I). The duration of a fast glider swoop is around $3 \mathrm{~s}$, which implies a lift force of around 30 times gravity $(30 \mathrm{~g})$, much too large for an albatross. These exceedingly fast glider speeds clearly demonstrate how effective wind-shear gust soaring can be given the right circumstances. A Google search under "dynamic soaring" provides many relevant websites that discuss this topic. Windshear soaring can also be performed with horizontal wind shear.

Since an albatross crosses the shear layer twice during a typical $10 \mathrm{~s}$ swoop, the time scale of the $5 \mathrm{~m} / \mathrm{s}$ velocity increase and the corresponding energy pulse due to crossing 
the shear layer once is $5 \mathrm{~s}$. This is a much shorter time than the $\sim 40 \mathrm{~s}$ required for an equivalent velocity increase estimated for wave-slope soaring.

An albatross wind-shear soaring can and often does convert the increase in airspeed (kinetic energy) to a gain in height (potential energy) similar to the motion of a pendulum. The increase in wind speed $(5 \mathrm{~m} / \mathrm{s})$ across the wind-shear layer used in the above example could provide around $9 \mathrm{~m}$ of altitude gain (assuming no drag). The bird could then trade height for airspeed on descending back down to the ocean surface.

Temporal wind gusts, in contrast to the structure gusts encountered in gust soaring, can be used to gain additional energy. A faster-than-average wind-speed gust contains greater-than-average wind shear, through which a bird could swoop extracting a greaterthan-average amount of energy. The trick of temporal-gust soaring is to maximize time in gusts and minimize time in lulls. An albatross undoubtedly knows how to identify gusts - rougher water surface, blowing spray - to use for additional energy gain.

\subsection{Minimum wind shear required for sustained soaring}

The Rayleigh cycle of wind-shear soaring as shown in Figure 4 was used to model an albatross gust soaring in nearly-circular flight along a plane tilted slightly upward into the wind. The essential assumptions are that 1) the plane crosses the wind-shear layer at a small angle with respect to the horizon so that vertical motions can be ignored, 2) the mean airspeed and mean glide ratio can be used to represent flight in the circle, and most importantly, 3) conservation of energy in each layer requires a balance between the sudden increase of airspeed (kinetic energy) due to crossing the shear layer and the gradual loss of airspeed due to drag over half a loop, resulting in energy-neutral flight. The motion during each half loop is somewhat similar to a landing flare when a glider maintains constant altitude and airspeed is slowly dissipated by drag.

Conservation of energy indicates that the vertical increase of wind speed $(\Delta W)$ across the wind-shear layer required for energy-neutral wind-shear soaring is given by $\Delta W=$ 
$g t / 2\left(V / V_{z}\right)$, where $g$ is gravity, $t$ is the period $(10 \mathrm{~s})$ of the nearly-circular flight, and $V / V_{z}$ is the ratio of the bird's airspeed $(V)$ to sinking speed through the air $\left(V_{z}\right)$ (see appendix for details). The glide ratio, $V / V_{z}$, very closely equals lift/drag for values $\gg 1$ typical of albatross flight. Relevant values of airspeed $(V)$, sinking speed $\left(V_{z}\right)$, and glide ratio in the modeled Rayleigh cycle were calculated using the aerodynamical equations of motion (Lissaman, 2005, 2007; Torenbeek and Wittenberg, 2009) and the maximum glide ratio $V / V_{z}=21.2$, and associated cruise airspeed, $V_{c}=16.0 \mathrm{~m} / \mathrm{s}$, of a wandering albatross (Diomedea exulans) in straight flight (Pennycuick, 2008) (Tables 1 and 2, appendix). The minimum $\Delta W$ for the Rayleigh cycle was found to be $3.55 \mathrm{~m} / \mathrm{s}$ with an associated average airspeed $V=16.0 \mathrm{~m} / \mathrm{s}$, average glide ratio $V / V_{z}=13.8$, and average bank angle of $45.7^{\circ}$ in the circle.

The $16.0 \mathrm{~m} / \mathrm{s}$ average airspeed in the circle and the $\Delta W=3.55 \mathrm{~m} / \mathrm{s}$ increase of airspeed encountered by a bird crossing the wind-shear layer indicate that the bird's airspeeds before and after crossing the wind-shear layer are $V_{l}=14.22 \mathrm{~m} / \mathrm{s}$ and $V_{2}=17.78 \mathrm{~m} / \mathrm{s}$. These values are greater than the airspeed of minimum sinking speed in the circle $(14.12$ $\mathrm{m} / \mathrm{s}$ ), and they fall within the range of the nearly constant values of $V / V_{z}(13.6-13.9)$ and $\Delta W(3.5-3.6 \mathrm{~m} / \mathrm{s})$ in Table 1 , which justifies the use of averages of airspeed, glide ratio $\left(V / V_{z}\right)$, and $\Delta W$ in modeling the nearly-circular flight.

The minimum wind shear $\Delta W$ calculated above is based on the $10 \mathrm{~s}$ observed swoop period. However, minimum $\Delta W$ is a function of loop period. The optimum loop period for absolute minimum $\Delta W$ in the Rayleigh cycle was found to be $7.25 \mathrm{~s}$, and this coincides with the cruise airspeed of $16.0 \mathrm{~m} / \mathrm{s}$ and bank angle of $54.7^{\circ}$. The absolute minimum $\Delta W$ is $3.36 \mathrm{~m} / \mathrm{s}$ (appendix, Table 3 ).

\subsection{Discussion of minimum wind shear $(\Delta W)$}

Why is the observed period (10 s) of an albatross swoop greater than the $7.2 \mathrm{~s}$ loop period associated with the absolute minimum $\Delta W$ in the Rayleigh cycle? An obvious answer is that the 10 s observed swoop period was of birds soaring in wind shears $(\Delta W)$ 
larger than the absolute minimum, and that given sufficiently large $\Delta W$ a bird flies with a larger loop period in order to reduce aerodynamic wing loading. It is possible that for a given $\Delta W$ greater than the absolute minimum a bird increases its swoop period to control energy gain in order to maintain an average airspeed of around $16 \mathrm{~m} / \mathrm{s}$. An implication is that an albatross trying to wind-shear gust soar near the absolute minimum wind shear $(3.4 \mathrm{~m} / \mathrm{s})$ needed for energy-neutral soaring must reduce the period of swoops from $10 \mathrm{~s}$ toward $7.2 \mathrm{~s}$ in order to continue soaring.

The minimum amount of wind shear $(\Delta W=3.4-3.5 \mathrm{~m} / \mathrm{s})$ across the wind-shear layer found above is small enough to suggest that the associated total wind speed might not be fast enough to generate large waves with sharp crests required for gust soaring and that therefore gust soaring might not be an appropriate model for such low wind-shear values. However, in the presence of decreasing winds, which had generated large waves, or in the presence of large swell propagating into an area from elsewhere, the waves might be sufficiently large and sharp enough with the addition of local wind waves to generate lee eddies, which can be used for gust soaring. In addition, lee eddies not associated with a separated boundary layer could be present and useful for gust soaring (more on this below).

The value of absolute minimum $\Delta W$ determined with the simple model described above closely agrees with results of a study by Lissaman (personal communication, 2010), who integrated the aerodynamic equations to determine the minimum increase of wind speed for energy-neutral wind-shear soaring in the Rayleigh two-layer case (Table 3). He found a minimum $\Delta W$ of $3.36 \mathrm{~m} / \mathrm{s}$ (same as present study) for a loop with the end point located downwind of the starting point, similar to the simple model described above. The loop period associated with this minimum $\Delta W$ is $7.35 \mathrm{~s}$, and the (constant) bank angle is $54^{\circ}$, very close to the values found in the present study. In another case, Lissaman (personal communication, 2010) forced the end point of a cycle to match the starting point in order to eliminate leeway in a circuit, and he found that the minimum $\Delta W$ increased slightly to $3.56 \mathrm{~m} / \mathrm{s}$ and the loop period increased to $7.70 \mathrm{~s}$ (Table 3 ). 
Sachs (2005) modeled an albatross soaring in a logarithmic wind profile and estimated the minimum wind velocity required for energy-neutral wind-shear soaring to be around $9 \mathrm{~m} / \mathrm{s}$ at a reference height of $10 \mathrm{~m}$. The increase of wind speed $(\Delta W)$ encountered by the simulated bird was $3.8 \mathrm{~m} / \mathrm{s}$ (Table 3 ) over the actual range of heights flown in the model swoop, 1.5-20 m above sea level. Most of the wind shear in a logarithmic profile below $20 \mathrm{~m}$ height is located within 1.5 meters of the ocean surface (Fig. 2) and was missed because the simulated bird did not fly closer to the surface than this height due to the bird's long wings. This suggests that Sachs' (2005) minimum reference wind speed of 9 $\mathrm{m} / \mathrm{s}$ overestimates the minimum wind speed required for gust soaring, which includes the large shear located in the lower part of the shear layer. Lissaman (2005) included the lower part of an exponential wind profile and found a rather similar minimum $\Delta W$ of 3.7 $\mathrm{m} / \mathrm{s}$ over the heights flown, 0-18 $\mathrm{m}$ (Table 3). This estimate using the whole wind profile $(0-18 \mathrm{~m})$ appears to be a better model of gust soaring since the simulated bird starts and ends at the bottom of the shear layer. The implication is that the minimum wind velocity at a height of $10 \mathrm{~m}$ required for sustained gust soaring in a smooth wind profile over the ocean is only around $3.4 \mathrm{~m} / \mathrm{s}$ (Lissaman, 2005) not $9 \mathrm{~m} / \mathrm{s}$ (Sachs, 2005). These results of the minimum $\Delta W=3.7-3.8 \mathrm{~m} / \mathrm{s}$, based on smooth wind profiles, imply that the simple Rayleigh cycle $(\Delta W=3.4-3.5 \mathrm{~m} / \mathrm{s})$ is also a fairly good approximation for a bird soaring in the reduced wind shear region located higher above sea level.

Important missing ingredients in these numerical simulations of wind-shear soaring are updrafts, separated boundary layers, and lee eddies that real albatrosses appear to exploit. An advantage of the gust-soaring technique is that a bird dives down into a lee eddy across the strongest part of the wind-shear layer and then climbs upward across it again (Figs. 3 and 4), thereby making good use of the available wind shear. In Sachs' (2005) simulation of wind-shear soaring, the albatross missed most of the strong wind shear located close to the ocean surface. Another advantage of gust soaring is that a bird remains below the wind-shear layer for part of the loop, thereby minimizing leeway. This could be an advantage for a bird trying to soar upwind.

\subsection{Mean travel velocity}


The mean travel velocity of an albatross gust soaring was modeled by dividing the Rayleigh cycle into semi-circular pieces and connecting a series of them together in a snaking flight pattern to simulate the observed zigzag flight. For example, a clockwise semi-circle located above the shear layer was connected to a counter-clockwise semicircle located below the shear layer to simulate flight in a direction $60^{\circ}$ to the right of the wind as illustrated in Figure 5A. A bird was assumed to quickly switch banking directions during the climbs and descents. The $16.0 \mathrm{~m} / \mathrm{s}$ mean airspeed in the series of connected semi-circles results in a mean travel velocity through the air of $2 \mathrm{~V} / \pi=10.2$ $\mathrm{m} / \mathrm{s}$. During the half loop located in the upper layer, a bird is carried downwind by the wind at a speed of $\Delta W$ so that the end point of a loop is displaced downwind of the starting point. This results in an average leeway over a loop equal to half of the wind speed in the two layers $(\Delta W / 2)$, which equals $1.8 \mathrm{~m} / \mathrm{s}$ for flight perpendicular to the wind.

Travel velocity was calculated for mean flight directions oriented at various angles with respect to the wind direction (Table 4). It was assumed that the average airspeed of $16.0 \mathrm{~m} / \mathrm{s}$ and the maximum glide ratio in the flight remain constant, and that as the mean flight direction through the air varies from being perpendicular to the wind, which is the most efficient course for gaining energy, an increase of wind shear $\Delta W$ is required to sustain soaring. The increase is needed because the bird would cross the wind-shear layer at an angle with respect to the wind direction, resulting in a smaller increase of airspeed for a given amount of wind shear. A complication is that real flown "semicircles" could depart from the assumed semicircles. Results are displayed as a travel velocity polar diagram in the shape of a valentine (Fig. 6), which gives travel velocity in any direction relative to the wind. Although this type of diagram is common for sailboats, Figure 6 appears to be the first one based on model simulations of an albatross sailing through the wind. The valentine can be compared with the observations of Alerstam et al. (1993, their Fig. 11), plotted as a similar diagram.

Results shown in Figures 6 and 7 and Table 4 indicate that a mean travel velocity can be in any direction relative to the wind given sufficient wind shear $(\Delta W)$, including 
directly upwind, although this direction is not the fastest way to travel upwind. The fastest upwind travel velocity is $6.2 \mathrm{~m} / \mathrm{s}(\Delta W=6.8 \mathrm{~m} / \mathrm{s})$ in a direction $\sim 30^{\circ}$ relative to the wind. This suggests that the fastest way to soar directly upwind is by tacking like a sailboat through angles of $\sim 30^{\circ}$ to the right and left of the wind direction. Tacking upwind with this angle can also be accomplished with less wind shear than by flying on a mean course directly upwind $(\Delta W=10.6 \mathrm{~m} / \mathrm{s})$. Table 4 also indicates that an albatross tacking at an angle of $50^{\circ}$ relative to the wind can soar upwind at $5.4 \mathrm{~m} / \mathrm{s}$, faster than the wind speed $(\Delta W=4.9 \mathrm{~m} / \mathrm{s})$ located at the top of the wind-shear layer. Tacking refers to the bird alternating the mean travel velocity to the left and right of the wind direction, not the $10 \mathrm{~s}$ zigzag swoops along the mean travel velocity.

The fastest model travel speed is directly downwind at $15.5 \mathrm{~m} / \mathrm{s}(\Delta W=10.6 \mathrm{~m} / \mathrm{s})$, although it is almost as fast ( $\sim 12-13 \mathrm{~m} / \mathrm{s})$ to travel obliquely downwind at angles of $140^{\circ}-165^{\circ}$ relative to the wind in $\Delta W=4.3-6.8 \mathrm{~m} / \mathrm{s}$ (Table 4, Fig. 7). Flying at these angles requires only around half the minimum wind shear for direct downwind flight (Table 4 , Fig. 7) and would maximize distance over the ocean at these $\Delta W$ s for foraging and circumnavigations. The most efficient directions to fly, as defined by the travel airspeed divided by $\Delta W$ being greater than 2.5 , are $80^{\circ}-150^{\circ}$ over the ocean, or directions extending from nearly perpendicular to the wind to obliquely downwind, with the most efficient direction at around $110^{\circ}$ relative to the wind.

Travel velocities given above used a $16.0 \mathrm{~m} / \mathrm{s}$ airspeed. If wind shear were greater than the minimum $\Delta W$ for soaring in a particular direction (Table 4, Fig. 7), then in principle an albatross could gain additional energy during a swoop and use it to fly faster than 16.0 $\mathrm{m} / \mathrm{s}$. Thus, the travel velocities in Table 4 and Figures 6 and 7 could underestimate real albatross travel velocities in larger wind shears. For example, the mean travel velocity perpendicular to the wind could be $\sim 22 \mathrm{~m} / \mathrm{s}$ in wind shear $(\Delta W)$ equal to $7 \mathrm{~m} / \mathrm{s}$, which is twice the minimum shear required for travel velocity perpendicular to the wind at 10.2 $\mathrm{m} / \mathrm{s}$. However, albatrosses do not appear to fly this fast (Wakefield et al., 2009) probably because of the large associated aerodynamic forces acting on the bird's wings at fast airspeeds. For example, a travel velocity of $22 \mathrm{~m} / \mathrm{s}$ corresponds to an airspeed of $35 \mathrm{~m} / \mathrm{s}$, 
bank angle of $66^{\circ}$, and lift force of $2.5 \mathrm{~g}$, which is almost twice that encountered with an airspeed of $16 \mathrm{~m} / \mathrm{s}$ and bank angle of $45^{\circ}$.

In summary, the model Rayleigh snaking cycle indicates that an albatross can fly in any direction including directly upwind when tacking is combined with travel velocities. Upwind flight velocity can be faster than the wind speed located at the top of the windshear layer when flying at angles of $40-60^{\circ}$ relative to the wind (Table 4$)$. Wind shears that are larger than the minimum wind shear for energy-neutral soaring could enable an albatross to fly faster the than travel velocities calculated for minimum wind shear, but albatrosses do not appear to do this. Instead, they appear to control airspeed in order to limit aerodynamic force on their wings.

\subsection{Discussion of travel velocity}

The across-wind travel velocity calculated above $(10.2 \mathrm{~m} / \mathrm{s})$ was based on a simplified Rayleigh cycle consisting of a series of linked semi-circles and average airspeed, bank angle, and glide ratio. Lissaman (personal communication, 2010) numerically simulated the details of a Rayleigh cycle loop and circuit. The implied across-wind travel velocity of the loop is $10.0 \mathrm{~m} / \mathrm{s}$, close to that found above (Table 3). The implied travel velocity of the Rayleigh cycle circuit is somewhat smaller than this $(8.8 \mathrm{~m} / \mathrm{s})$ because the bird was forced to return to the starting position. Sachs (2005), using a logarithmic wind profile,

found an across-wind travel velocity of $9.2 \mathrm{~m} / \mathrm{s}$ and a leeway of $9.0 \mathrm{~m} / \mathrm{s}$. This across-wind value is somewhat slower than the Rayleigh cycle loop because Sachs used smaller values of glide ratio (20) and cruise velocity $(12.6 \mathrm{~m} / \mathrm{s})$ (Table 3). Sachs' leeway value is much larger than that for the Rayleigh cycle because the simulated bird remains in the region of fast wind speeds above $1.5 \mathrm{~m}$ in elevation. This could be advantageous for a bird trying to fly downwind but a disadvantage in trying to fly upwind. The resulting travel velocity over the ocean is $12.9 \mathrm{~m} / \mathrm{s}$ in a direction $134^{\circ}$ relative to the wind.

Some of the albatrosses I observed soared upwind at the same speed $(\sim 6 \mathrm{~m} / \mathrm{s})$ as our ship steamed upwind, which matches the upwind travel velocity $\left(6 \mathrm{~m} / \mathrm{s}\right.$ at $\left.25-40^{\circ}\right)$ of the 
Rayleigh cycle (Figs. 6 and 7). Alerstam et al. (1993) report observed albatross travel velocities in a travel polar diagram very similar to those estimated with the Rayleigh cycle, including across-wind travel speed of $10.2 \mathrm{~m} / \mathrm{s}$ (in wind speeds of $8-13 \mathrm{~m} / \mathrm{s}$ ) compared to $10.2 \mathrm{~m} / \mathrm{s}$ in the Rayleigh cycle (Fig. 6). The fastest travel velocity observed by Alerstam et al. was $22 \mathrm{~m} / \mathrm{s}$ at a downwind angle of $140^{\circ}$ and in fast wind speeds of 13$20 \mathrm{~m} / \mathrm{s}$, compared to a travel velocity of $12 \mathrm{~m} / \mathrm{s}$ in the Rayleigh cycle. However, this fast observed speed no doubt includes a large downwind leeway velocity.

Wakefield et al. (2009) found a strong linear relationship between the ground speed of albatrosses and the wind-speed component in the direction of flight. For example, the travel velocity through the air of wandering albatrosses was found to equal an average 10 $\mathrm{m} / \mathrm{s}$ plus 0.4 times the wind component (at $5 \mathrm{~m}$ height) in the direction of flight. Values for the Rayleigh cycle (Table 4) give a similar $10 \mathrm{~m} / \mathrm{s}$ travel velocity through the air and a similar linear relationship with the wind-speed component $(\Delta W)$ in the direction of flight, indicating that the Rayleigh cycle is a good model for observed albatross flight speeds. The observed speeds suggest that albatrosses generally fly with a $10 \mathrm{~m} / \mathrm{s}$ travel velocity through the air even in relatively fast winds $(6-9 \mathrm{~m} / \mathrm{s})$ and large wind shear. The implication is that the birds control the amount of energy gain in wind-shear soaring in order to maintain a nearly-constant average airspeed.

In order to fly with a $10 \mathrm{~m} / \mathrm{s}$ travel velocity in wind shear that is much larger than the minimum required for energy-neutral soaring at that airspeed (Table 4), an albatross must modify its flight to gain less energy than the maximum possible. To reduce energy gain a bird could increase the period of its swoops. It could climb less high through the windshear layer or could remain in the weak wind shear located higher up in the wind profile as modeled by Sachs (2005). A bird could also cross the wind-shear layer with a large horizontal angle relative to the wind direction.

In principle, an albatross could fly on a nearly-straight course perpendicular to the wind and also in other directions but not directly upwind or downwind by using the net energy gained from climbing and descending across the wind-shear layer. A hypothetical flight pattern might consist of the following: A bird flying eastward (for example) in the 
lower layer below a north wind of $8.7 \mathrm{~m} / \mathrm{s}$ rises into the upper layer. As the bird encounters the wind velocity, airspeed increases by $\Delta V=2.3 \mathrm{~m} / \mathrm{s}$, and the relative wind shifts $\sim 30^{\circ}$ in an upwind direction. The bird quickly turns (yaws) left and heads into the relative wind to avoid side slipping. It then banks slightly $\left(\sim 10^{\circ}\right)$ to the right and turns eastward by the end of the $5 \mathrm{~s}$ half loop. During the $5 \mathrm{~s}$ turn, airspeed decreases by 2.3 $\mathrm{m} / \mathrm{s}$ due to drag. The bird then descends into the lower layer and encounters another increase of airspeed $(\Delta V=2.3 \mathrm{~m} / \mathrm{s})$ and a shift of the relative wind $\sim 30^{\circ}$ in a downwind direction. The bird quickly turns (yaws) right to head into the relative wind and then banks slightly $\left(\sim 10^{\circ}\right.$ degrees) to the left and turns eastward again, etc. The airspeed increase $(\Delta V=2.3 \mathrm{~m} / \mathrm{s})$ for nearly-straight flight is smaller than the minimum $(\Delta V=3.5$ $\mathrm{m} / \mathrm{s}$ ) for the Rayleigh cycle because of the smaller bank angle and larger glide ratio in the nearly-straight flight. The resulting travel velocity over the ocean would be $15.5 \mathrm{~m} / \mathrm{s}$ at a direction of $105^{\circ}$ relative to the wind.

This hypothetical flight trajectory suggests that the snaking Rayleigh cycle is 2.5 times more efficient at increasing energy (smaller required $\Delta W$ ) than the nearly-straight acrosswind flight. More importantly, it indicates that the general rule of wind-shear soaringclimbing headed upwind and descending headed downwind — can be relaxed given sufficiently-large wind shear. Furthermore, it suggests that an albatross could control energy gain and airspeed by reducing the curvature (smoothing) of the Rayleigh semicircular snaking flight pattern to make it straighter as illustrated in Figure 6C and D and as observed by Idrac $(1924,1931)$. Along with straighter flight come a smaller bank angle and smaller aerodynamic force, which would be less stressful for a bird.

\section{Wave-slope soaring}

A common perception is that updrafts over a wave are caused mainly by wind flowing up the windward face of a wave (see Pennycuick, 1982; Wilson, 1975). However, the causes and structures of updrafts are considerably more complicated than this and include air displaced upward by the orbital velocity of the wave surface and vertical velocities from wind-wave interactions. These can occur simultaneously, their effects adding and 
subtracting from each other in complicated ways. Soaring using any updraft caused by wind interacting with waves is referred here to be "wave-slope soaring," realizing that this term is a simplification. A bird flying horizontally in an updraft over waves could gain altitude (potential energy) from the wind. This energy gain could be used to balance the bird's loss of energy due to drag in energy-neutral flight.

The following summarizes observations of albatross soaring and model simulations of wind over waves with the intent to infer methods of wave-slope soaring. First, when the air is still and the seas calm, albatrosses are observed to usually sit on the ocean surface or, infrequently, fly by alternating flapping and gliding (Pennycuick, 1982; Alerstam et al., 1993). This indicates that thermals are not effective for albatross soaring or that albatrosses have not learned how to soar in thermals, which seems unlikely.

Reports of albatrosses soaring over swell waves in zero wind (Alerstam et al., 1993; Froude, 1888; Pennycuick, 1982) illustrate that the orbital velocity of the wave surface forces a substantial updraft over the slope of a wave facing its direction of propagation. Froude estimated an updraft velocity of around $1 \mathrm{~m} / \mathrm{s}$ above a wave of wavelength $150 \mathrm{~m}$, amplitude $1.5 \mathrm{~m}$, period $10 \mathrm{~s}$, and phase speed $15 \mathrm{~m} / \mathrm{s}$. Since the minimum sinking rate of a wandering albatross is around $0.6 \mathrm{~m} / \mathrm{s}$ (Pennycuick, 2008), this bird could easily soar over these waves in zero wind. The trick in wave-slope soaring is to maximize the time in the strongest updrafts and minimize time outside this region especially in downdrafts. By flying in the strongest updrafts an albatross could gradually increase its airspeed over the airspeed of minimum sink and use the excess either to climb or to fly in an across-wave direction through a downdraft.

When a swell wave propagates in an upwind direction then the updraft created by wind flowing up the windward wave face is added to the updraft due to the orbital motion of the wave surface. This would provide an ideal situation for sustained wave-slope soaring that could be accomplished with smaller waves than those required to soar in zero wind. A similar situation of enhanced updraft occurs when a swell wave propagates downwind 
faster than the wind speed. Sullivan et al. (2008) describe model simulations and observations that include illustrations of updrafts over swell waves.

A fast wind flowing over a relatively slow wave can cause an updraft over the windward wave face, but the updraft is countered somewhat by a downward orbital velocity there. Leeward of the wave crest and centered just upwind of the wave trough a lee eddy can form (Fig. 8), which is a region of closed streamlines centered about the critical layer and synchronous with the wave (Sullivan et al., 2000). The updraft region located over the leeward wave face is forced mainly by upward orbital velocity of the wave surface. Sometimes the lee eddy is known as a cat's eye for its distinctive pattern as shown in Figure 8. The region of closed streamlines in the lee eddy deflects the outer mean streamlines away from the wave surface creating a region of updraft over the eddy (Fig. 8). Sullivan et al., (2000) show streamlines for three examples corresponding to the increasing ratio of wave speed to wind speed, $c / u *=3.9,7.8$ and 11.5 , where $c$ is the wave phase speed and $u *$ is the friction velocity. As the ratio increases, the cat's-eye pattern thickens, its center moves upward and upwind toward the wave crest, and the region of updraft shifts upwind to extend vertically over the wave crest. Hristov et al. (2003) also show observations and model calculations of wave-induced lee eddies, which include an updraft over the lee side of a wave below the critical layer, forced mainly by the orbital velocity, and extending over the wave crest above the critical layer. Lee-eddy structures and the associated pressure perturbations are thought to be important in generating wind waves.

The waves modelled by Sullivan et al. (2000) are sinusoidal. Wind waves tend to have sharper crests than this and can break in sufficient wind speed. When swift wind blows over a sharp-crested wave or a breaking wave, streamlines can separate from the wave as described by Pennycuick (2002) and shown in Figure 3. The resulting lee eddy or separation bubble contains closed clockwise streamlines (illustrated very schematically in Fig. 3) and thus a region of updraft along the leeward face of the wave due to the orbital velocity and upslope wind. Other examples of lee eddies are shown by Hsu et al. (1981, Fig.15), Gent and Taylor, (1977, Figs 2, 3, 7, 8), Reul et al. (1999, Fig.1). Vertical 
velocities of 1.0 to $1.2 \mathrm{~m} / \mathrm{s}$ have been measured in lee eddies downwind of sharp-crested and breaking waves associated with a free-stream wind velocity of $6 \mathrm{~m} / \mathrm{s}$ (Kawai, 1982; Reul et al., 1999). The updraft associated with lee eddies might explain the observations by Idrac $(1925,1931)$ of some albatrosses soaring there as part of low-level flight in a swoop.

Three main points of this discussion add to previous descriptions of albatross waveslope soaring as follows: 1) Lee eddies with updrafts can form downwind of a wave crest with or without a separated boundary layer (Figs. 3 and 8). 2) An updraft region is often located over the leeward slope of a wave and over a lee eddy, not just over the windward slope of a wave. The regions of updrafts over the leeward and windward wave slopes and the wave crest merge and extend upwards above a wave crest (Fig. 8). 3) Starting in the lower part of a lee eddy, an albatross can climb upwind over a wave crest and descend downwind back into the lee eddy (wind-shear gust soaring) and remain in a region of updraft during the whole swoop. Combining both wind-shear soaring and wave-slope soaring in this maneuver would maximize total energy gain in a swoop. This would be very useful for soaring in low wind speeds.

\section{Relative Energy gain from the two soaring techniques}

The gain of energy in wave-slope soaring during a typical swoop in a typical updraft was estimated crudely by assuming that an albatross spends around half of each swoop in a $1 \mathrm{~m} / \mathrm{s}$ updraft over waves (as discussed above), resulting in an average vertical velocity of $0.5 \mathrm{~m} / \mathrm{s}$ (over a swoop). During the $5 \mathrm{~s}$ of a half swoop this vertical velocity would result in a height gain of $2.5 \mathrm{~m}$, assuming horizontal flight through the air. In the same $5 \mathrm{~s}$ of a half swoop the bird could gain $9 \mathrm{~m}$ from wind-shear gust soaring as estimated above for an increase in wind speed of $5 \mathrm{~m} / \mathrm{s}$ across the wind-shear layer or could gain $20 \mathrm{~m}$ for an increase of wind speed of $10 \mathrm{~m} / \mathrm{s}$ across the wind-shear layer. These values indicate that wind-shear soaring during a swoop in these typical conditions in the Southern Ocean (Table 2) provides around 4-8 times more energy than wave-slope soaring or $80-90 \%$ of 
the total. Of course, in zero wind $100 \%$ of the energy for soaring would have to come from wave-slope soaring.

The energy gained from wave-slope soaring during a swoop could be critical to soaring in smaller wind shears. For example, if wind shear fell below a certain threshold ( $\Delta W \sim$ $3.4 \mathrm{~m} / \mathrm{s}$ ) below which energy-neutral soaring could not exist by itself, wave-slope soaring could provide the additional energy to make soaring possible. In such a situation the bird would need to combine the two techniques as observed by Alerstam et al. (1993), Pennycuick (1982), and this present study. During the lower part of a swoop albatrosses often fly very close to the surface of a wave with a wingtip just grazing the water surface. This is interpreted to be how a bird maximizes the effect of wave-slope soaring by flying both in the region of maximum updraft to gain energy and in ground effect to reduce energy loss from wingtip vortices and downwash.

\section{Summary}

The general rules of albatross soaring are: 1) No wind, no waves, no soaring; 2) Waveslope soaring can be accomplished in swell without wind; 3) Wind-shear soaring can be accomplished in wind without waves. 4) Wave-slope soaring and wind-shear soaring are usually combined when wind and waves coexist. In "typical conditions" in the Southern Ocean (Table 2), consisting of an increase of wind speed $\sim 5-10 \mathrm{~m} / \mathrm{s}$ across the windshear layer and an updraft velocity $\sim 1 \mathrm{~m} / \mathrm{s}$, wind-shear soaring provides around $80-90 \%$ of the energy for soaring.

The albatrosses I observed appeared to use both wind-shear and wave-slope soaring techniques. The birds periodically flew very close to the ocean surface along the windward face of a wave, which is interpreted to be wave-slope soaring. They then turned sharply upwind and pulled up just downwind of another wave, climbed above the windward face of that wave, banked steeply to turn downwind then descended toward the windward side of that wave; this is interpreted to be wind-shear gust soaring. Wave-slope soaring might also have been used during the climb and descent. Each swoop crossed 
twice through the wind-shear layer, once by climbing into the wind and once by descending downwind (or obliquely downwind), so that energy was gained on both crossings. The lower across-wind part of the swoop appeared to coincide with the windward face of a wave, where fast airspeeds could lead to large sinking rates. Flying in the updraft region of a wave during this part of the swoop provides a gain in energy where none is possible from wind shear. Winds interacting with waves can generate eddy structures, which can be used by an albatross to wave-slope soar over the leeward face and over the crest of waves in combination with gust soaring.

A simple dynamical model based on the Rayleigh (1883) cycle of wind-shear soaring and Pennycuick's (2002) concept of gust soaring over waves was developed to simulate the observed zigzag flight pattern. The Rayleigh cycle indicates that albatrosses can soar in any direction including directly upwind, although across-wind and down-wind flight is faster. Simulated travel velocities in different directions were shown in a travel velocity polar diagram (Fig. 6), which is somewhat similar to ones generated for sailboats but a first for albatrosses. Mean travel velocity perpendicular to the wind is around $10.2 \mathrm{~m} / \mathrm{s}$. Maximum upwind velocity of $6.2 \mathrm{~m} / \mathrm{s}$ can be achieved by a bird tacking through angles of $30^{\circ}$ relative to the wind. The minimum increase of wind speed across the thin windshear layer necessary for energy-neutral soaring at $16.0 \mathrm{~m} / \mathrm{s}$ airspeed was estimated to be around $3.5 \mathrm{~m} / \mathrm{s}$ for across-wind flight with a $10 \mathrm{~s}$ period (Table 4, Fig. 7). This result agrees closely with some detailed numerical simulations of albatross flight by Lissaman (personal communication, 2010) (Table 3). In large wind shear an albatross modifies its flight pattern in order to limit energy gain, airspeed, and aerodynamical force on its wings.

Real albatross flight patterns appear to combine both wind-shear gust soaring and wave-slope soaring, which suggests that models that exclude waves and wind-wave interactions do not simulate real albatross flight. The simple Rayleigh cycle modeled here, which includes the effect of waves by simulating gust soaring through a detached wind-shear boundary layer, captures the essential dynamics of wind-shear soaring and appears to reproduce quite well the observed features of albatross soaring, including 
realistic travel speeds in all directions, even upwind velocity faster than the wind speed at the top of the wind-shear layer. The model Rayleigh cycle balances the sudden gain of airspeed (kinetic energy) due to crossing the wind-shear layer in gust soaring with the gradual loss of airspeed due to drag during each half loop and simply illustrates how an albatross can use wind shear to soar in different directions.

\section{Conclusions}

My conclusion about the relative importance of the two soaring techniques has evolved since I first watched albatrosses soaring over the South Atlantic Ocean and thought they mainly used updrafts over waves. I now believe they mainly use wind-shear in gust soaring, except in light winds and in the presence of significant swell. Convincing evidence of the overall importance of the wind-shear soaring technique is given by modeling studies of wind-shear soaring (Lissaman, 2005; Sachs, 2005) including the simple Rayleigh cycle described above, the gust-soaring concept developed by Pennycuick (2002), the exceedingly fast RC glider speeds obtained by wind-shear gust soaring downwind of ridges, and the large relative energy gain from wind shear estimated here for a swoop in "typical conditions" in the Southern Ocean. Albatrosses appear to combine both soaring techniques in their swooping flight, with wave-slope soaring providing additional energy gain on the lower across-wind flight path where no energy gain is possible from wind-shear soaring and possibly additional energy gain in updrafts during the upper part of a swoop over a wave crest.

To further investigate the soaring techniques of albatrosses, it would be helpful to instrument them to measure in high resolution their positions, orientations, velocities over the ground and through the air as well as information about wind and wave fields. If these kinds of data were obtained they might also provide new information about the interactions of wind and waves and wave generation. Models of albatross soaring would be improved by including waves and the interactions of wind and waves, which could help provide information about gust soaring and the wave-slope-soaring part of a swoop. 
Interpreting such model simulations could be difficult since even model simulations of albatross soaring that exclude waves have been a challenge to interpret.

\section{Acknowledgements}

Funds for the R/V Seward Johnson cruise were provided by National Science Foundation Grant OCE95-28574. I was stimulated to study albatross soaring by reading Carl Safina's book (Safina, 2002) and his National Geographic piece (Safina, 2007), which led me to investigate wind-shear soaring and discover many papers, websites, and YouTube videos that discuss it. Colin Pennycuick generously made available copies of his papers, his book, and his video of albatross soaring; discussions with him on email motivated me to estimate the energy sources of soaring flight and to model the Rayleigh cycle and gust soaring. Peter Lissaman generously provided copies and interpretations of his papers and a tutorial about the aerodynamics of gliding flight. Colleen Hurter obtained many of the books and papers used in this study, and Paul Oberlander helped draft the figures. Peter Lissaman, David Fisichella, Bill Hallstein, Jim Price, Tony Sturges, and two anonymous reviewers read an earlier version of the paper and provided helpful comments.

\section{Appendix}

\section{Modeled Rayleigh cycle}

In the modeled Rayleigh cycle (Fig. 4) the loss of energy over a half loop $(t / 2=5 \mathrm{~s})$ is given by $m g(t / 2) V_{z}$, where $m$ is mass, $g$ is gravity, $t$ is the period of a loop, and $V_{z}$ is the bird's sinking speed through the air due to drag. Conservation of energy for energyneutral soaring requires that this energy loss must equal the sudden gain in kinetic energy (airspeed) from crossing the wind-shear layer, which is given by $m\left(V_{2}^{2}-V_{I}^{2}\right) / 2$, where $V_{I}$ is the airspeed before crossing the wind-shear layer, and $V_{2}$ is the airspeed after crossing the layer. In this latter term, $V_{2}{ }^{2}-V_{1}{ }^{2}=\left(V_{2}-V_{l}\right)\left(V_{2}+V_{l}\right)$. $V_{2}+V_{l}$ is assumed to equal twice the average airspeed $(2 V)$ in the nearly-circular flight, and $V_{2}-V_{l}$ is the increase of 
airspeed, $\Delta V$, of a bird crossing the wind-shear layer, which is assumed to equal the vertical increase of wind speed $(\Delta W)$ across the layer. Conservation of energy and the approximations given above indicate that

$$
\Delta V=\frac{g t}{2\left(V / V_{\mathrm{z}}\right)},
$$

where $V / V_{z}$ is the glide ratio averaged over $5 \mathrm{~s}$ of a half loop and over $\Delta V$.

The decrease in airspeed at constant height during a half loop was obtained by balancing the rate of change of airspeed (kinetic energy) with dissipation due to drag. This balance indicates that $d V / d t=g /\left(V / V_{z}\right)$. Since $V / V_{z}$ is virtually constant in the relevant airspeed range $\Delta V$ centered on the cruise airspeed of $16.0 \mathrm{~m} / \mathrm{s}$ (Table 1), airspeed decreases linearly in time. Therefore, the total decrease of airspeed, $\Delta V$, in a half loop $(t / 2)$ is equal to $g t / 2\left(V / V_{z}\right)$ as derived above (Eq. A1).

Values of $V / V_{z}$ for circular flight were calculated using a quadratic drag law (drag proportional to lift squared), the aerodynamic equations of motion (Lissaman, 2005; Torenbeek and Wittenberg, 2009), the maximum glide ratio $\left(V / V_{z}\right) \max =21.2$, and the associated cruise airspeed $V_{c}=16.0 \mathrm{~m} / \mathrm{s}$ of a wandering albatross in straight flight (Pennycuick, 2008). Specifically, values of $V / V_{z}$ were calculated using

$$
V / V_{z}=\frac{2\left(V / V_{z}\right) \max }{\left(V / V_{c}\right)^{2}+\left(V_{c} / V \cos \varphi\right)^{2}},
$$

where $\varphi$ is the bank angle. For balanced circular flight, $\cos \varphi$ is given by

$$
\cos \varphi=\sqrt{\frac{1}{(2 \pi V / g t)^{2}+1}} .
$$

The airspeed at minimum sink rate in straight flight was found by setting the derivative $\mathrm{d} V_{z} / \mathrm{d} V$ (Eq. A2) equal to zero and solving for $V$, which is given by $V=$ $0.760 V_{c}=12.2 \mathrm{~m} / \mathrm{s}$. The minimum sink rate $\left(V_{z}=0.66 \mathrm{~m} / \mathrm{s}\right)$ at this airspeed is achieved 
with a large lift coefficient. The airspeed of minimum sink rate in a balanced circle was calculated using this same lift coefficient and by assuming that the added lift required to balance centrifugal force in the turn is provided by an increase of airspeed. This results in the airspeed of minimum sink rate (often called minimum power) in a $10 \mathrm{~s}$ circle being given by $V=0.760 V_{c} / \sqrt{ } \cos \varphi=14.1 \mathrm{~m} / \mathrm{s}$ (Tables 1 and A1). The minimum sink rate at this airspeed is $V_{z}=1.04 \mathrm{~m} / \mathrm{s}$. These values are close to those corresponding to the minimum height loss in a circle, which occurs at a bank angle $\varphi=45.0^{\circ}$. Using $\varphi=45.0^{\circ}$ and $V=$ $0.760 V_{c} / \sqrt{ } \cos \varphi$, we find that values for minimum height loss in a circle are $t=9.26 \mathrm{~s}, V=$ $14.5 \mathrm{~m} / \mathrm{s}$, and $V_{z}=1.11 \mathrm{~m} / \mathrm{s}$ (Table A1).

The minimum $\Delta V$ (and $\Delta W$ ) for an energy-neutral Rayleigh loop was determined by first calculating a $\Delta V$ using the $V / V_{z}$ at $16.0 \mathrm{~m} / \mathrm{s}$ cruise airspeed in the loop (Table 1) and then calculating average values for that range in airspeeds $(\Delta V)$ centered on an airspeed of $16.0 \mathrm{~m} / \mathrm{s}$, etc. The minimum vertical increase of wind speed across the wind-shear layer for a $10 \mathrm{~s}$ loop was found to be $\Delta W=3.55 \mathrm{~m} / \mathrm{s}$; this value corresponds to an average $V / V_{z}=13.8$, average equivalent $V_{z}=1.14 \mathrm{~m} / \mathrm{s}$, and average $\varphi=45.6^{\circ}$ (Table A1). The Rayleigh cycle is based on a constant height loop (zero sink); the value for $V_{z}$ given above is the equivalent sink rate that would balance drag if $\mathrm{d} V / \mathrm{d} t=0$.

The minimum airspeed loss $\Delta V$ (and $\Delta W$ ) calculated above for energy-neutral soaring used the observed $10 \mathrm{~s}$ loop period. However, minimum $\Delta V$ is a function of the loop period, and there is an absolute minimum $\Delta V$, which occurs at the cruise airspeed $V_{c}=$ $16.0 \mathrm{~m} / \mathrm{s}$ and at an optimum loop period $t_{\text {opt }}$, given by

$$
t_{o p t}=\frac{\pi V_{c} \sqrt{2}}{g}=7.25 \mathrm{~s} .
$$

Equation A4 was derived by setting the derivative $\mathrm{d}(\Delta V) / \mathrm{d} t$ (Eq. A1) equal to zero and solving for $t$. At $t_{o p t}$ and $V_{c}=16.0 \mathrm{~m} / \mathrm{s}$, the glide ratio in the loop is just one half of the maximum glide ratio in straight flight, and the equivalent sink rate $(1.51 \mathrm{~m} / \mathrm{s})$ in the loop is equal to twice the sink rate $(0.755 \mathrm{~m} / \mathrm{s})$ at $16.0 \mathrm{~m} / \mathrm{s}$ in straight flight. The small 
optimum loop period (7.25 s) results in more frequent crossings of the shear layer and a larger rate of energy gain than that in the $10 \mathrm{~s}$ loop.

Using $t_{\text {opt }}$ and $V_{c}=16.0 \mathrm{~m} / \mathrm{s}$, the absolute minimum $\Delta V$ (and $\Delta W$ ) was found to be

$$
\Delta V=\frac{\pi V_{c} \sqrt{2}}{\left(V / V_{z}\right) \max }=3.35 \mathrm{~m} / \mathrm{s} .
$$

Equation A5 can be simplified to $\Delta V=\pi V_{z} \sqrt{2}$, where $V_{z}$ is the sinking speed $(0.755 \mathrm{~m} / \mathrm{s})$ corresponding to $\left(V / V_{z}\right)$ max. Values for the absolute minimum $\Delta V$ in a Rayleigh cycle loop were calculated as averages within the $\Delta V$ range in airspeeds $(3.35 \mathrm{~m} / \mathrm{s})$ centered on $16.0 \mathrm{~m} / \mathrm{s}$. The absolute minimum $\Delta V($ and $\Delta W)=3.36 \mathrm{~m} / \mathrm{s}$; this value corresponds to an average $V / V_{z}=10.6$, average equivalent $V_{z}=1.51 \mathrm{~m} / \mathrm{s}$, and average $\varphi=54.7^{\circ}$ (Table A1).

\section{References}

Alerstam, T., Gudmundsson, G. A., Larsson, B., 1993. Flight tracks and speeds of Antarctic and Atlantic seabirds: radar and optical measurements. Philosophical transactions of the Royal Society of London B 340, 55-67.

Croxall, J. P., Silk, J. R. D., Phillips, R. A., Afanasyev, V., Briggs, D. R., 2005. Global circumnavigations: Tracking year-round ranges of nonbreeding albatrosses. Science 307, 249-250.

Froude, W., 1888. On the soaring of birds. Proceedings of the Royal Society of Edinburgh 15, 256-258.

Gent, P. R., Taylor, P. A., 1977. A note on "separation" over short wind waves. Boundary-Layer Meteorology 11, 65-87. 
Hanley, K. E., Belcher, S. E., Sullivan, P. P., 2010. A global climatology of wind-wave interactions. Journal of Physical Oceanography 40, 1263-1282.

Hristov, T. S., Miller, S. D., Friehe, C. A., 2003. Dynamical coupling of wind and ocean waves through wave-induced air flow. Nature, 422, 55-58.

Hsu, C.-T., Hsu, E. Y., Street, R. L., 1981. On the structure of turbulent flow over a progressive water wave: theory and experiment in a transformed, wave-following coordinate system. Journal of Fluid Mechnanics 105, 87-117.

Idrac, P., 1925. Étude expérimentale et analytique du vol sans battements des oiseaux voiliers des mers australes, de l'Albatros en particulier. La Technique Aeronautique 16, 9-22.

Idrac, P., 1931. Études expérimentales sur le vol à voile au lieu même d'évolution des grands oiseaux voiliers (vauturs, albatros, etc.); son application au vol à voile humain. Vivien, Paris, pp. 75.

Kawai, S., 1982. Structure of air flow separation over wind wave crests. Boundary-Layer Meteorology 23, 503-521.

Lissaman, P., 2005. Wind energy extraction by birds and flight vehicles. American Institute of Aeronautics and Astronautics Paper 2005-241, January 2005, pp. 13.

Lissaman, P., 2007. Fundamentals of energy extraction from natural winds. Technical Soaring 31(2), 36-41.

Pennycuick, C. J., 1982. The flight of petrels and albatrosses (Procellariiformes), observed in South Georgia and its vicinity. Philosophical Transactions of the Royal Society of London B 300, 75-106. 
Pennycuick, C. J., 2002. Gust soaring as a basis for the flight of petrels and albatrosses (Procellariiformes). Avian Science 2, 1-12.

Pennycuick, C. J., 2008. Modelling the flying bird. Academic Press, New York, pp. 496.

Rayleigh, J. W. S., 1883. The soaring of birds. Nature 27, 534-535.

Reul, N., Branger, H., Giovanangeli, J.-P., 1999. Air flow separation over unsteady breaking waves. Physics of Fluids 11(7), 1959-1961.

Sachs, G., 2005. Minimum shear wind strength required for dynamic soaring of albatrosses. Ibis 147, 1-10.

Safina, C., 2002. Eye of the albatross: Visions of hope and survival. Henry Holt \& Company, New York, pp. 377.

Safina, C. 2007. On the wings of the albatross. National Geographic, 212 (December 2007), 96-113.

Sullivan, P. P., Edson, J. B., Hristov, R., McWilliams, J. C., 2008. Large-eddy simulations and observations of atmospheric marine boundary layers above nonequilibrium surface waves. Journal of the Atmospheric Sciences 65, 1125-1245.

Sullivan, P. P., McWilliams, J. C., Moeng, C.-H., 2000. Simulations of turbulent flow over idealized water waves. Journal of Fluid Mechanics 404, 47-85.

Torenbeek, E., Wittenberg, H., 2009. Flight Physics: Essentials of Aeronautical Disciplines and Technology, with Historical Notes. Springer, New York, pp. 535. 
Wakefield, E. D., Phillips, R. A., Matthiopoulos, J., Fukuda, A., Higuchi, H., Marshall, G. J., Trathan, P. N., 2009. Wind field and sex constrain the flight speeds of central-place foraging albatrosses. Ecological Monographs 79, 663-679.

Wilson, J. A., 1975. Sweeping flight and soaring by albatrosses. Nature 257, 307-308.

Young, I. R., 1999. Seasonal variability of the global ocean wind and wave climate.

International Journal of Climatology 19, 931-950. 
Table 1. Characteristics of circular flight and the minimum wind speed increase $(\Delta W)$ across the wind-shear layer required for energy-neutral soaring in a Rayleigh cycle $(t=10 \mathrm{~s})$.

\begin{tabular}{cccccc}
\hline $\begin{array}{c}\text { Airspeed } \\
\text { in circle, } \\
V(\mathrm{~m} / \mathrm{s})\end{array}$ & $\begin{array}{c}\text { Bank } \\
\text { angle } \varphi\end{array}$ & $\begin{array}{c}\text { Sinking } \\
\text { speed } V_{z} \\
(\mathrm{~m} / \mathrm{s})\end{array}$ & $\begin{array}{c}\text { Glide ratio } \\
\text { in circle } \\
\left(V / V_{z}\right)\end{array}$ & $\begin{array}{c}\text { Wind speed } \\
\text { increase } \Delta W \\
(\mathrm{~m} / \mathrm{s})\end{array}$ & Comments \\
\hline 14.1 & 42.1 & 1.04 & 13.7 & 3.6 & Minimum sink rate \\
15.0 & 43.8 & 1.08 & 13.8 & 3.5 & Maximum glide ratio \\
16.0 & 45.7 & 1.15 & 13.9 & 3.5 & \\
17.0 & 47.4 & 1.23 & 13.8 & 3.5 & \\
18.0 & 49.1 & 1.32 & 13.6 & 3.6 & \\
19.0 & 50.6 & 1.42 & 13.4 & 3.7 & \\
20.0 & 52.0 & 1.53 & 13.0 & 3.8 & \\
21.0 & 53.4 & 1.66 & 12.6 & 3.9 & \\
22.0 & 54.6 & 1.80 & 12.2 & 4.0 & \\
23.0 & 55.8 & 1.95 & 11.8 & 4.2 & \\
24.0 & 57.0 & 2.12 & 11.3 & 4.3 & \\
25.0 & 58.0 & 2.30 & 10.9 & 4.5 & \\
26.0 & 59.0 & 2.50 & 10.4 & 4.7 & \\
27.0 & 60.0 & 2.71 & 10.0 & 4.9 & \\
28.0 & 60.9 & 2.93 & 9.6 & 5.1 & \\
29.0 & 61.7 & 3.17 & 9.1 & 5.4 & \\
30.0 & 62.5 & 3.43 & 8.7 & 5.6 & \\
& & & & & \\
\hline
\end{tabular}

Values for circular flight were calculated using a quadratic drag law, the maximum glide ratio (21.2) and associated cruise airspeed $\left(V_{c}=16.0 \mathrm{~m} / \mathrm{s}\right)$ of straight flight for a wandering albatross (Pennycuick, 2008) (see appendix). Minimum sink rate was calculated with $V=0.760 V_{c} / \sqrt{ } \cos \varphi$. 
Table 2. Characteristics of a wandering albatross (Diomedea exulans), the ultimate soaring bird.

Mass: $10 \mathrm{~kg}$

Maximum wing span: $3.5 \mathrm{~m}$ (largest of all birds)

Wing aspect ratio: 15

Straight flight characteristics (Pennycuick, 2008):

Maximum glide ratio: 21.2 at cruise airspeed of $16.0 \mathrm{~m} / \mathrm{s}$ and sink rate of $0.755 \mathrm{~m} / \mathrm{s}$

Minimum sink rate: $0.624 \mathrm{~m} / \mathrm{s}$ at airspeed $11.5 \mathrm{~m} / \mathrm{s}$ and glide ratio 18.4

Range: Ten million kilometers. This range is based on a bird flying $2 / 3$ of the time at an average travel velocity of $10 \mathrm{~m} / \mathrm{s}$ for 50 years and is equivalent to approximately 400 circumnavigations in the latitude band of the Southern Ocean.

Life span: 50 years

Food: Squid, fish, krill

Nesting sites: Islands in the Southern Ocean

Distribution at sea: Most albatross species, including wandering albatrosses, forage over the Southern Ocean between latitudes $30-60^{\circ} \mathrm{S}$.

Albatross flight: As a result of their long, narrow, high aspect ratio ( 12-15) wings, albatrosses have the largest glide ratios (horizontal velocity/vertical velocity) and are the greatest soaring birds. A shoulder lock system holds their wings in a horizontal position so that little energy is expended while soaring (Pennycuick, 1982). Soaring efficiency enables the heart rate of a soaring albatross to be close to the basal heart rate when resting. Most albatross species lack the muscles to undertake sustained flapping flight and thus are dependent on obtaining energy from the wind for sustained soaring. In contrast, most petrels, which are smaller than albatrosses, have smaller wing aspect ratios $(<10)$ and tend to flap-glide (Pennycuick, 1982).

Typical winds and waves in the Southern Ocean: Maximum average wind speeds, located near $50^{\circ} \mathrm{S}$, are westerly at $\sim 11 \mathrm{~m} / \mathrm{s}$. Maximum average significant wave heights near $50^{\circ} \mathrm{S}$ are $\sim 5 \mathrm{~m}$. Wind speeds and wave heights decrease from this latitude southward towards Antarctica and northward towards $30^{\circ} \mathrm{S}$, where values of average wind speed are $\sim 6-7 \mathrm{~m} / \mathrm{s}$ and average significant wave heights are $\sim 2 \mathrm{~m}$. Thus, typical average wind speeds in the Southern Ocean are 6-11 m/s and typical average wave heights are 2-5 m (Young, 1999; Hanley et al., 2010). Based on these values, this paper used wind speeds of 5-10 m/s and a wave height of $3 \mathrm{~m}$ (period 9-10 s) as approximate "typical conditions" in order to crudely estimate the relative energy gains from windshear soaring and wave-slope soaring. An updraft of approximately $1 \mathrm{~m} / \mathrm{s}$ is generated by the orbital motion of a $3 \mathrm{~m}$ wave (period $\sim 9.5 \mathrm{~s}$ ) and wind-wave interactions as described in the text. 
Table 3. Minimum increase of wind speed $\Delta W$ required for energy-neutral wind-shear soaring.

\begin{tabular}{|c|c|c|c|c|c|c|c|}
\hline $\begin{array}{l}\text { Wind } \\
\text { Profile }\end{array}$ & $\begin{array}{l}\text { Max } \\
V / V_{z} \\
\end{array}$ & $\begin{array}{c}V_{c} \\
(\mathbf{m} / \mathbf{s})\end{array}$ & $t(\mathbf{s})$ & $\begin{array}{c}\Delta \boldsymbol{W} \\
(\mathbf{m} / \mathbf{s})\end{array}$ & $\begin{array}{c}\text { Travel } \\
\text { Vel }(\mathbf{m} / \mathbf{s})\end{array}$ & $\begin{array}{c}\text { Flight } \\
\text { Cycle }\end{array}$ & Reference \\
\hline Rayleigh & 21.2 & 16.0 & 10.0 & 3.55 & 10.2 & Loop & This paper \\
\hline Rayleigh & 21.2 & 16.0 & 7.25 & 3.36 & 10.2 & Loop & This paper \\
\hline Rayleigh & 21.2 & 16.0 & 7.35 & 3.36 & 10.0 & Loop & $\begin{array}{l}\text { Lissaman (pers. } \\
\text { com.) }\end{array}$ \\
\hline Rayleigh & 21.2 & 16.0 & 7.70 & 3.58 & 8.8 & Circuit & $\begin{array}{l}\text { Lissaman (pers. } \\
\text { com.) }\end{array}$ \\
\hline Exponential & 25.0 & 15.0 & -- & 3.74 & -- & Circuit & Lissaman (2005) \\
\hline Logarithmic & 20.0 & 12.6 & 6.9 & 3.8 & 9.2 & Snaking & Sachs (2005) \\
\hline
\end{tabular}

The Rayleigh wind profile has two layers with zero wind in the lower layer and a wind speed of $\Delta W$ in the upper layer. For the exponential and logarithmic profiles, the listed increase of wind speed $(\Delta W)$ is over the range of heights flown, 0-18 $\mathrm{m}$ (Lissaman, 2005), 1.5-20 m (Sachs, 2005). Maximum glide ratio $\left(V / V_{z}\right)$ and the associated cruise airspeed $\left(V_{c}\right)$ for straight flight define the glide polar (see appendix). Values consistent with a wandering albatross, $V / V_{z}=21.2, V_{c}=16.0$ (Pennycuick, 2008), were used in this table where possible. The period of a flight cycle is $t$, and the observed swoop period is $10 \mathrm{~s}$. The absolute minimum $\Delta W$ for a Rayleigh cycle loop occurs at a period of $7.25 \mathrm{~s}$. Travel velocities are perpendicular to the wind velocity and consist of averages over two half loops, assuming that the half loops could be connected in a snaking cycle. A "circuit" returns to the starting height, velocity, and ground position. A "loop" returns to the starting height and velocity but not ground position because of leeway. 
Table 4. Travel velocity and the increase of wind speed $(\Delta W)$ across the wind-shear layer required for Rayleigh snaking flight in different directions $(\theta)$ relative to the wind direction.

\begin{tabular}{|c|c|c|c|c|c|c|c|}
\hline \multirow{2}{*}{$\begin{array}{l}\text { Travel } \\
\text { direction } \\
\text { through } \\
\text { the air } \\
\text { relative to } \\
\text { wind } \theta\end{array}$} & \multirow[t]{2}{*}{$\begin{array}{c}\text { Increase of } \\
\text { wind speed } \\
\Delta W(\mathrm{~m} / \mathrm{s})\end{array}$} & \multicolumn{3}{|c|}{ Upwind velocity } & \multirow{2}{*}{$\begin{array}{c}\text { Across- } \\
\text { wind } \\
\text { velocity } \\
(10.2) \sin (\theta) \\
(\mathrm{m} / \mathrm{s})\end{array}$} & \multicolumn{2}{|c|}{$\begin{array}{l}\text { Travel velocity over } \\
\text { the ocean } \\
\text { (course made good) }\end{array}$} \\
\hline & & $\begin{array}{c}\text { Leeway } \\
\Delta W / 2 \\
(\mathrm{~m} / \mathrm{s})\end{array}$ & $\begin{array}{c}(10.2) \cos (\theta) \\
(\mathrm{m} / \mathrm{s})\end{array}$ & $\begin{array}{l}\text { Sum of } \\
\text { components } \\
(\mathrm{m} / \mathrm{s})\end{array}$ & & $\begin{array}{c}\text { Speed } \\
(\mathrm{m} / \mathrm{s})\end{array}$ & $\begin{array}{l}\text { Direction } \\
\text { Relative to } \\
\text { wind }\end{array}$ \\
\hline 0 & 10.6 & -5.3 & 10.2 & 4.9 & 0.0 & 4.9 & 0 \\
\hline 10 & 8.5 & -4.2 & 10.0 & 5.8 & 1.8 & 6.1 & 17 \\
\hline 20 & 6.8 & -3.4 & 9.6 & 6.2 & 3.5 & 7.1 & 30 \\
\hline 30 & 5.7 & -2.8 & 8.8 & 6.0 & 5.1 & 7.9 & 40 \\
\hline 40 & 4.9 & -2.4 & 7.8 & 5.4 & 6.6 & 8.5 & 51 \\
\hline 50 & 4.3 & -2.2 & 6.6 & 4.4 & 7.8 & 9.0 & 61 \\
\hline 60 & 4.0 & -2.0 & 5.1 & 3.1 & 8.8 & 9.4 & 71 \\
\hline 70 & 3.7 & -1.9 & 3.5 & 1.6 & 9.6 & 9.7 & 80 \\
\hline 80 & 3.6 & -1.8 & 1.8 & 0.0 & 10.0 & 10.0 & 90 \\
\hline 90 & 3.5 & -1.8 & 0.0 & -1.8 & 10.2 & 10.3 & 100 \\
\hline 100 & 3.6 & -1.8 & -1.8 & -3.6 & 10.0 & 10.7 & 110 \\
\hline 110 & 3.7 & -1.9 & -3.5 & -5.4 & 9.6 & 11.0 & 119 \\
\hline 120 & 4.0 & -2.0 & -5.1 & -7.1 & 8.8 & 11.3 & 129 \\
\hline 130 & 4.3 & -2.2 & -6.6 & -8.7 & 7.8 & 11.7 & 138 \\
\hline 140 & 4.9 & -2.4 & -7.8 & -10.2 & 6.6 & 12.2 & 147 \\
\hline 150 & 5.7 & -2.8 & -8.8 & -11.7 & 5.1 & 12.7 & 156 \\
\hline 160 & 6.8 & -3.4 & -9.6 & -13.0 & 3.5 & 13.5 & 166 \\
\hline 170 & 8.5 & -4.2 & -10.0 & -14.3 & 1.8 & 14.4 & 173 \\
\hline 180 & 10.6 & -5.3 & -10.2 & -15.5 & 0.0 & 15.5 & 180 \\
\hline
\end{tabular}

Note: Mean airspeed in snaking flight is $16.0 \mathrm{~m} / \mathrm{s}$, and mean travel velocity through the air is $10.2 \mathrm{~m} / \mathrm{s}$. 
Table A1. Summary of flight characteristics of a wandering albatross.

\begin{tabular}{lcccccc}
\hline Flight characteristic & $t(\mathrm{~s})$ & $\varphi\left({ }^{\circ}\right)$ & $V(\mathrm{~m} / \mathrm{s})$ & $V_{z}(\mathrm{~m} / \mathrm{s})$ & $V / V_{z}$ & $\Delta W(\mathrm{~m} / \mathrm{s})$ \\
\hline Straight flight & & & & & & \\
$\quad$ Minimum sink rate & ----- & 0 & 12.2 & 0.66 & 18.4 & ----- \\
$\quad$ Maximum $V / V_{z}$ & ----- & 0 & 16.0 & 0.76 & 21.2 & ----- \\
$\quad \begin{array}{l}\text { Circular flight } \\
\quad \text { Minimum sink at } t=10 \mathrm{~s}\end{array}$ & 10.0 & 42.1 & 14.1 & 1.04 & 13.7 & ----- \\
$\quad$ Minimum height loss & 9.3 & 45.0 & 14.5 & 1.11 & 13.0 & ----- \\
$\quad$ Rayleigh cycle loop & & & & & & \\
$\quad$ Minimum $\Delta W$ at $t=10 \mathrm{~s}$ & 10.0 & 45.6 & 16.0 & 1.14 & 13.8 & 3.55 \\
$\quad$ Absolute minimum $\Delta W$ & 7.2 & 54.7 & 16.0 & 1.51 & 10.6 & 3.36 \\
\hline
\end{tabular}

Note that $t$ is the period of a loop (observed $t=10 \mathrm{~s}$ ), $\varphi$ is the bank angle, $V$ is the airspeed, $V_{z}$ is the sinking speed, $V / V_{z}$ is the glide ratio, and $\Delta W$ is the minimum increase of wind speed across the wind-shear layer needed for energy-neutral flight in a Rayleigh cycle loop. Values were calculated using a quadratic drag law, the aerodynamic equations of motion (Lissaman, 2005), the maximum glide ratio (21.1) and the associated cruise airspeed $(16.0 \mathrm{~m} / \mathrm{s}$ ) of a wandering albatross in straight flight (Pennycuick, 2008) (see appendix). A Rayleigh cycle is based on a constant height loop (zero sink); listed values of $V_{z}$ represent the equivalent sinking speeds due to drag, assuming that $\mathrm{d} V / \mathrm{d} t=0$. 


\section{Figure captions}

Figure 1. Schematic summary of the zigzag swooping flight pattern of an albatross soaring over waves observed during a cruise to the South Atlantic. The swooping motion is shown relative to the waves, which are moving downwind. Each climb is upwind and each descent is downwind since the waves are going downwind, although the downwind component is difficult to show in the figure and looks almost parallel to the wave crest. The average direction of flight has an upwind component. Schematic waves are uniform for simplicity; real ocean waves are much more complicated. Regions of updraft and downdraft due to wind blowing over waves are indicated schematically. The wave phase speed was not subtracted from the wind speed in this diagram. Simplified vectors of typical average wind velocity over the ocean surface are indicated in the right part of the figure. Most of the vertical gradient of wind velocity (wind shear) is located in a thin boundary layer near the ocean surface.

Figure 2. Vertical (logarithmic) profile of average wind speed over the ocean (after Sachs, 2005). An assumed reference velocity of $10 \mathrm{~m} / \mathrm{s}$ is located at a height of $10 \mathrm{~m}$. Note that most (72\%) of the increase of wind speed within the lowest $10 \mathrm{~m}$ of the profile is located in a $\sim 2 \mathrm{~m}$ thick wind-shear boundary layer near the surface (shaded layer).

Figure 3. Schematic of an albatross "gust soaring” (after Pennycuick, 2002). Starting in a lee eddy (or separation bubble) located downwind of a sharp-crested wave a bird climbs up through a thin wind-shear layer (separated boundary layer) that has detached from the wave crest. On crossing the wind-shear layer, the bird's airspeed abruptly increases, and the bird experiences a "gust." The increase in airspeed can be used to climb up to heights of 10-15 $\mathrm{m}$ by trading airspeed (kinetic energy) for height (potential energy). A lee eddy is a region of closed streamlines with clockwise circulation in this figure.

Figure 4. Idealized example of the airspeeds of a dragless albatross gust-soaring through a thin wind-shear layer, which is assumed to consist of an increase in wind speed from zero below the layer to $5 \mathrm{~m} / \mathrm{s}$ above. It shows how an albatross could gust soar in the 
region downwind of a wave crest as indicated in Figure 3. This schematic is based on the written description of Rayleigh (1883) who first suggested that a bird could continuously soar in nearly circular flight on an inclined plane that crosses a thin wind-shear layer.

Starting in the lower layer with an airspeed $15 \mathrm{~m} / \mathrm{s}$ a bird climbs upwind a short distance vertically across the wind-shear layer, which increases airspeed to $20 \mathrm{~m} / \mathrm{s}$. The bird then turns and flies downwind with the same airspeed of $20 \mathrm{~m} / \mathrm{s}$. During the turn, ground speed increases to $25 \mathrm{~m} / \mathrm{s}$ downwind and consists of the bird's $20 \mathrm{~m} / \mathrm{s}$ airspeed plus (tail) wind speed of $5 \mathrm{~m} / \mathrm{s}$. The bird descends downwind a short distance vertically across the wind-shear layer, which increases airspeed to $25 \mathrm{~m} / \mathrm{s}$. The bird turns upwind flying with an airspeed of $25 \mathrm{~m} / \mathrm{s}$. Thus one swoop through the wind-shear layer increases airspeed from $15 \mathrm{~m} / \mathrm{s}$ to $25 \mathrm{~m} / \mathrm{s}$ (two times the $5 \mathrm{~m} / \mathrm{s}$ wind speed increase). By descending upwind (dashed line) the bird's airspeed would have decreased from $20 \mathrm{~m} / \mathrm{s}$ back to $15 \mathrm{~m} / \mathrm{s}$ with no net gain in airspeed.

Figure 5. Plan view, showing examples of snaking (zigzag) flight at an angle of $60^{\circ}$ to the right of the wind similar to the flight shown in Figure 1. A) Rayleigh snaking cycle created by linking together semi-circular pieces of the circular Rayleigh cycle to simulate the observed albatross zigzag flight pattern (Fig. 1) and average travel velocity. B) Semicircular snaking cycle modified to cross the wind-shear layer parallel to the wind direction for maximum energy gain. C) Snaking cycle modified so that the upwind climb is parallel to the wind and the descent is obliquely downwind and parallel to wave crests; this pattern closely resembles my observations of albatross soaring and those of Idrac $(1925,1931)$. D) Snaking cycle further smoothed so that the climb is obliquely upwind and the descent is mainly across-wind (observed by Idrac, 1925, 1931). Flight patterns in panels $\mathrm{C}$ and $\mathrm{D}$ could be used to reduce energy gain in large wind shear $(\Delta W)$.

Figure 6. Travel velocity polar diagram in the shape of a valentine based on an average airspeed of $16.0 \mathrm{~m} / \mathrm{s}$ and the minimum wind shear $(\Delta W)$ values required for sustained soaring in different directions relative to the wind direction. Travel speed in a particular direction is given by the length of a line starting at the origin $(x=0, y=0)$ and ending on the valentine. For example, the travel speed in a direction $30^{\circ}$ to the right or left of the 
wind direction is $7.1 \mathrm{~m} / \mathrm{s}$, and the associated travel speed in an upwind direction is 6.2 $\mathrm{m} / \mathrm{s}$ (Table 4). Values were calculated using the Rayleigh snaking cycle shown in Figure $6 \mathrm{~A}$, a mean airspeed of $16.0 \mathrm{~m} / \mathrm{s}$, and leeway equal to the average wind speed of the two layers as given in Table 4. Two components of travel velocity were combined to create the valentine - the mean travel velocity through the air equal to $10.2 \mathrm{~m} / \mathrm{s}$ and the downwind leeway equal to $\Delta W / 2$.

Figure 7. Mean travel velocity over the ocean using an average airspeed of $16.0 \mathrm{~m} / \mathrm{s}$ plotted versus the angle between travel direction and the wind as shown in Figure 6. The associated minimum wind shear across the wind-shear layer $(\Delta W)$ required for energyneutral soaring in the different directions is also shown. Values were calculated using the Rayleigh snaking cycle shown in Figure 5A, a mean travel velocity of $10.2 \mathrm{~m} / \mathrm{s}$ and leeway equal to the average wind speed of the two layers $(\Delta W) / 2$ as given in Table 4 . The minimum wind speed increase across the sharp wind-shear layer required for energy neutral soaring $(t=10 \mathrm{~s})$ ranges from a minimum of $\Delta W=3.5 \mathrm{~m} / \mathrm{s}$ for across-wind flight to a maximum of $\Delta W=10.6 \mathrm{~m} / \mathrm{s}$ for flight directly upwind and downwind.

Figure 8. Example illustrating that wind blowing over a wave forms a lee eddy, which is a region of closed streamlines shaped like a cat's eye (after Sullivan, et al., 2000, their Figure 16b). In this example, wind speed at a height of one wavelength is equal to around four times the wave phase speed $c$, and $c / u_{*}=3.9$, where $u *$ is the friction velocity. The lee eddy is centered just upwind of the wave trough and deflects streamlines upwards above the eddy. Updraft wind velocity (shaded) is centered over the leeward (right) side of the wave, over the windward (left) side of the eddy, and extends upward over the lee eddy. The dotted line indicates the critical layer, where the wind changes direction, as viewed moving with the wave speed, from a downwind direction (to the right) above the critical layer to the opposite direction (to the left) below as caused by friction and surface boundary conditions. 
Gains

Altitude up to $15 \mathrm{~m}$

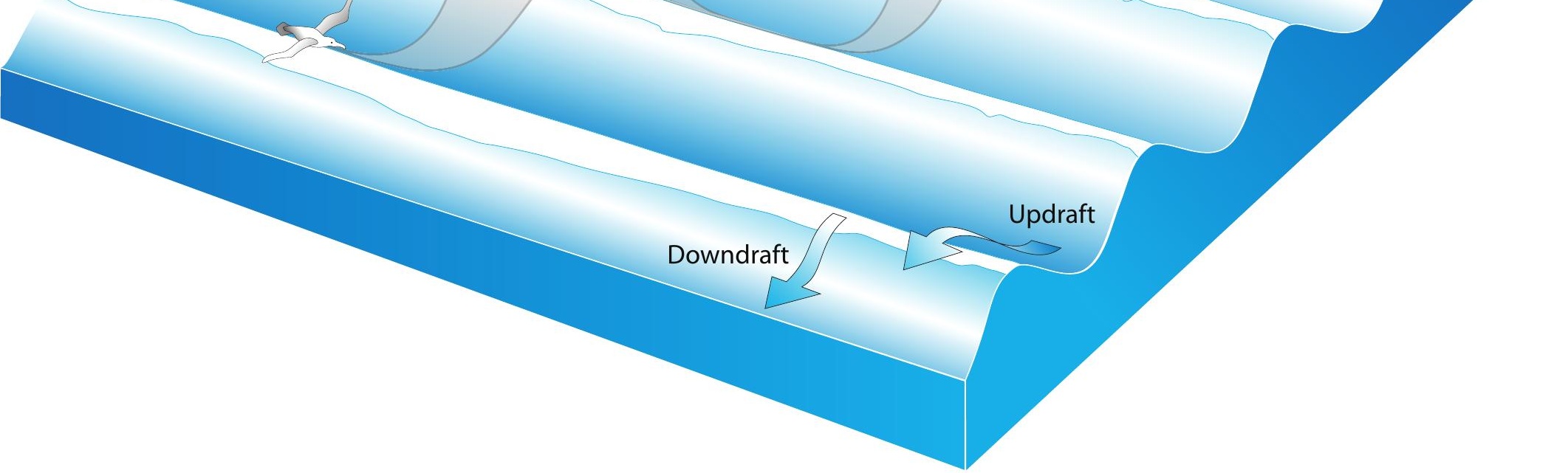




\section{Figure 3 \\ Figure 3}

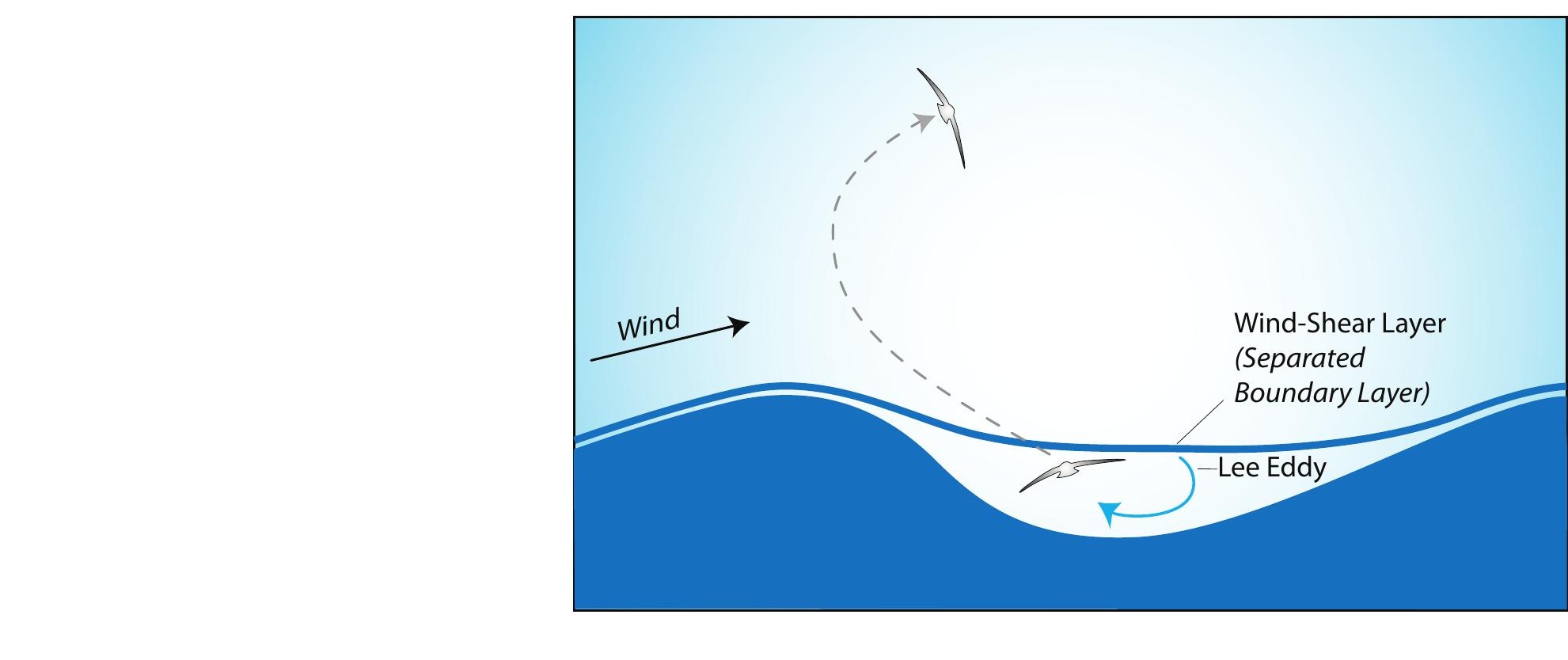

Wind-Shear Layer

(Separated

Boundary Layer)

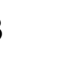

3

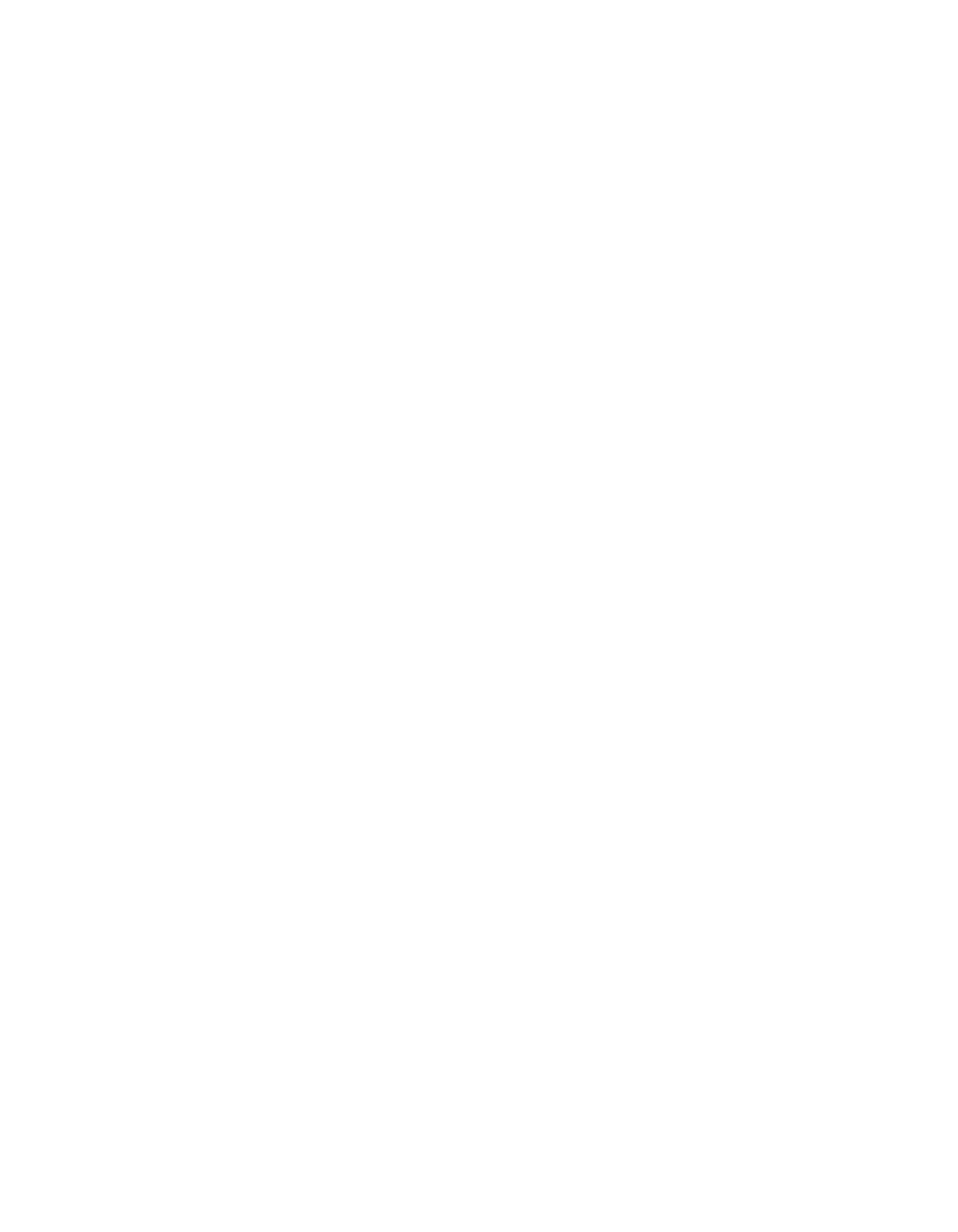




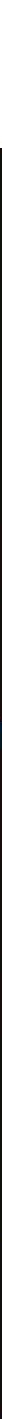

Figure 4

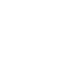

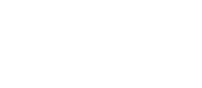

年

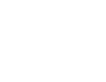
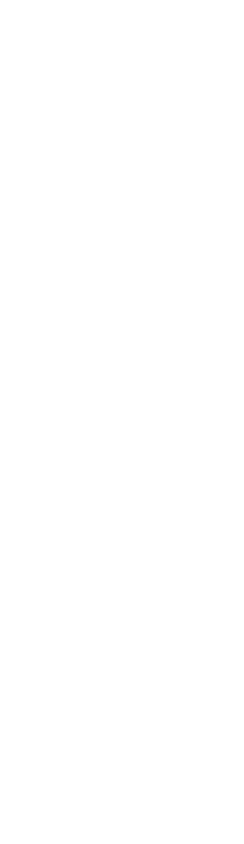

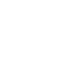

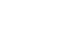

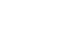

$\sqrt{2}+x^{2}$

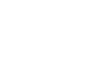

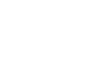

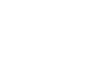

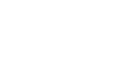
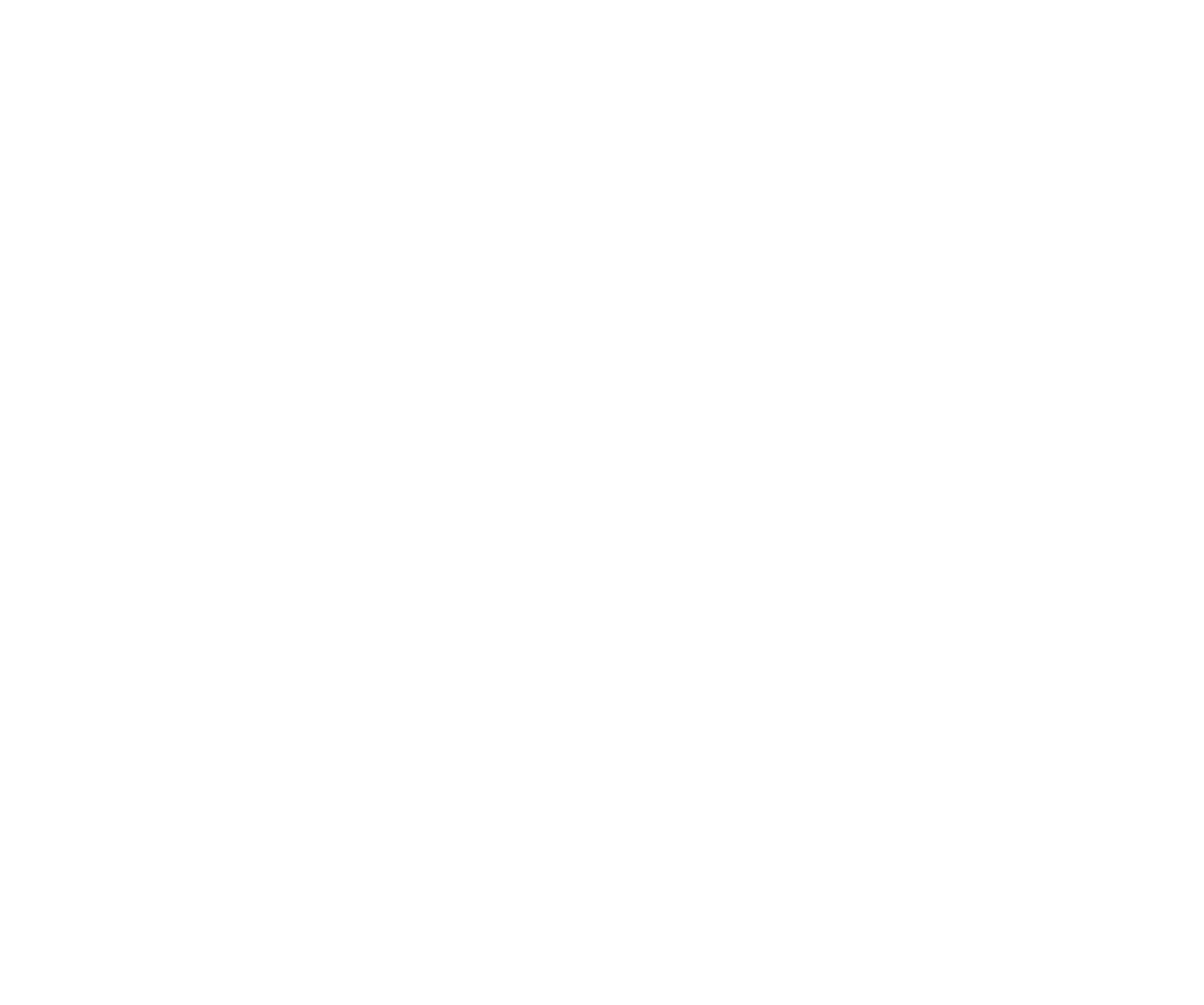
Albatross Travel Velocity and Minimum Wind Shear $(\Delta \mathrm{W})$

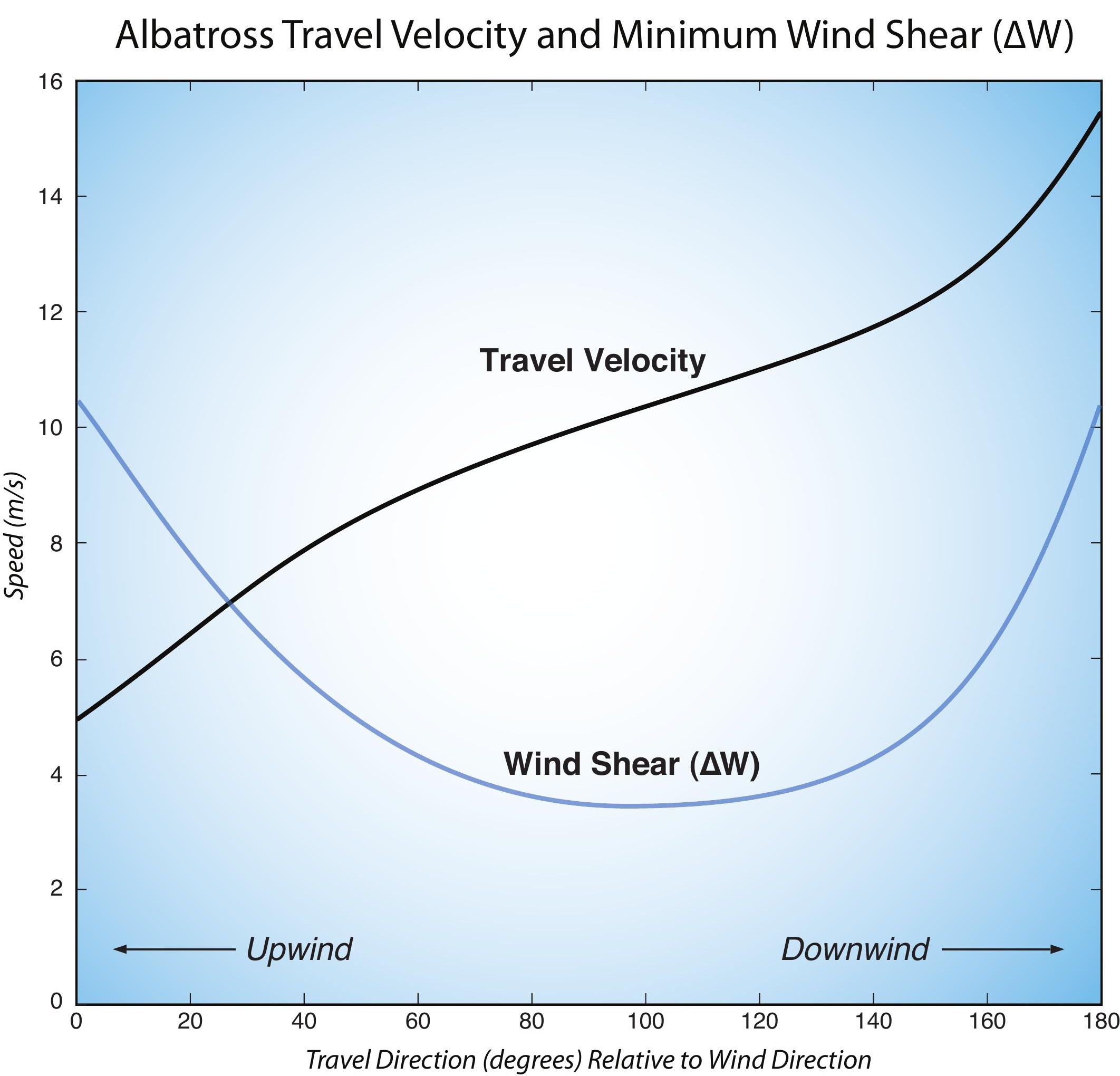




\section{Albatross Travel Velocity}

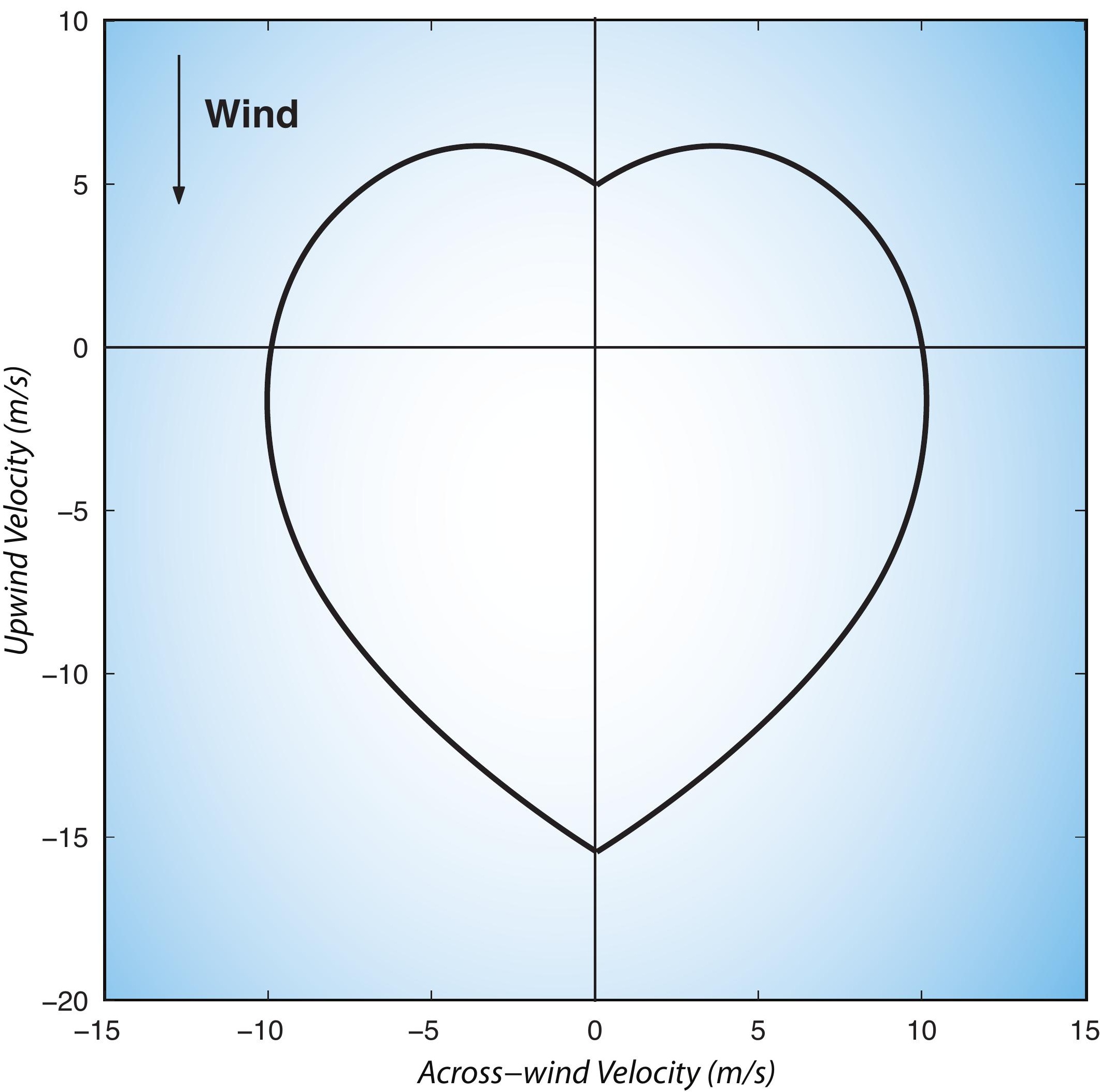




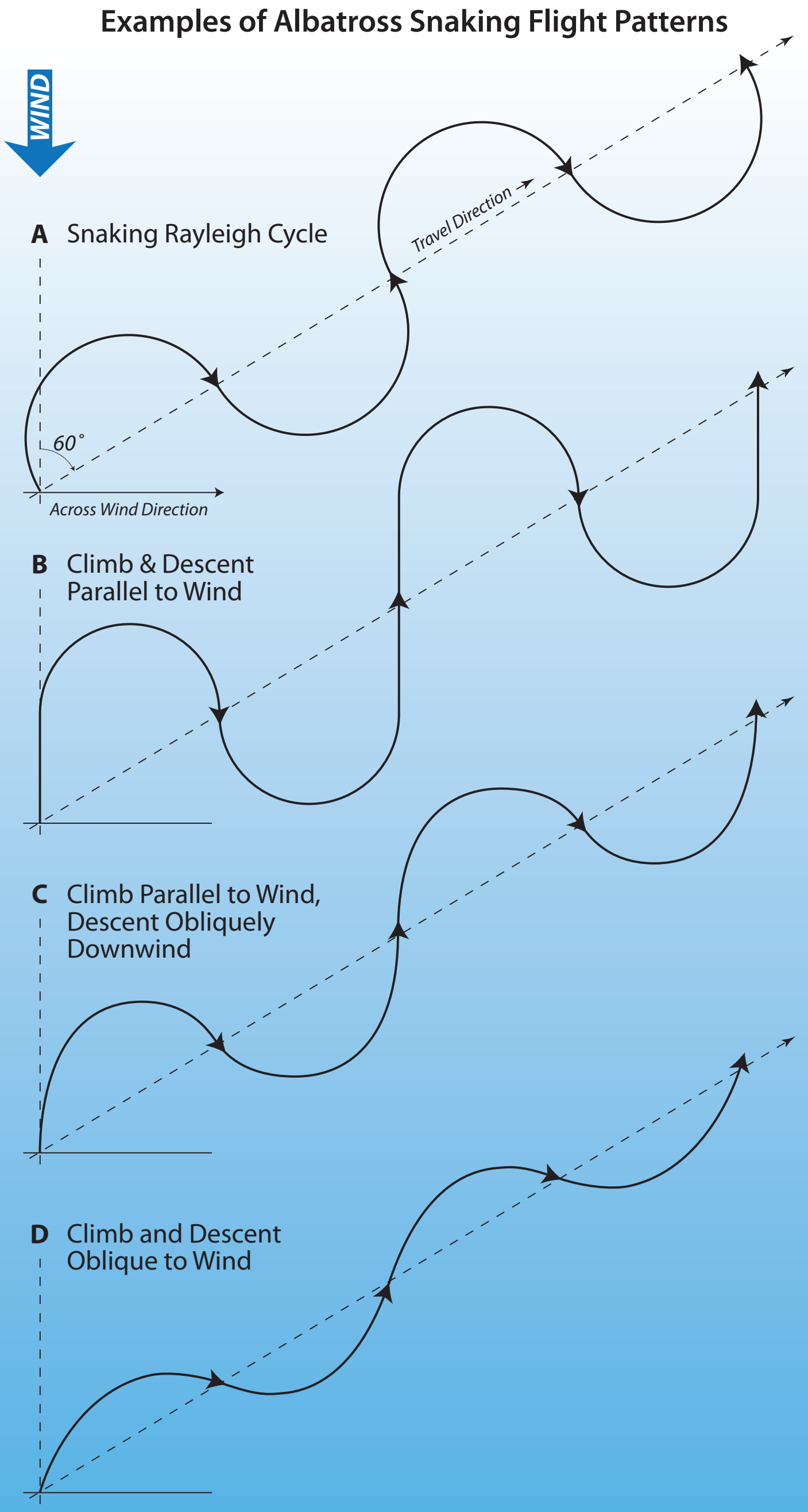




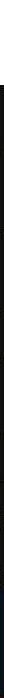

